Review

\title{
The chemistry of gut microbiome in health and diseases
}

\author{
Agnes Wei Yin Lau ${ }^{1}$, Loh Teng-Hern Tan ${ }^{1}$, Nurul-Syakima Ab Mutalib ${ }^{1,2}$, Sunny Hei Wong ${ }^{3}$, \\ Vengadesh Letchumanan ${ }^{1 *}$, Learn-Han Le ${ }^{1 *}$
}

\author{
Article History \\ ${ }^{1}$ Novel Bacteria and Drug Discovery (NBDD) Research Group, Microbiome \\ and Bioresource Research Strength (MBRS), Jeffrey Cheah School of \\ Received: 30 November \\ 2020; \\ Medicine and Health Sciences, Monash University Malaysia, 47500, Selangor \\ Darul Ehsan, Malaysia. \\ weiyin.agnes.0816@gmail.com (AW-Y.L); loh.teng.hern@monash.edu (LT- \\ Received in Revised Form: \\ HT); vengadesh.letchumanan1 @ monash.edu (VL); \\ 31 January 2021; \\ lee.learn.han@monash.edu (L-H.L) \\ Accepted: 2 February 2021; \\ ${ }^{2}$ UKM Medical Molecular Biology Institute (UMBI), UKM Medical Centre, \\ Universiti Kebangsaan Malaysia, Kuala Lumpur, Malaysia; \\ Available Online: 8 \\ February 2021 \\ syakima@ppukm.ukm.edu.my (N.-S.A.M) \begin{abstract}
China; wonghei@cuhk.edu.hk (S.H.W)
*Corresponding author: Vengadesh Letchumanan, vengadesh.letchumanan1@ monash.edu; Learn-Han Lee, lee.learn.han@monash.edu
\end{abstract} \\ ${ }^{3} \mathrm{Li}$ Ka Shing Institute of Health Sciences, Department of Medicine and \\ Therapeutics, The Chinese University of Hong Kong, Shatin, Hong Kong,
}

\begin{abstract}
There are trillions of microbes residing in our body, with their collective genomes much more than human genomes. They have been living in a close relationship with us and play a role in various biological functions. The human microbes begin to build up in utero, accumulate, and fluctuate until a set point is achieved around three years of age. The gut microbiome is altered by several factors, which include age, diet, and antibiotic use. After the exposure, the microbe may shift back to retain its balance, but some factors may leave a permanent footprint on the gut flora. This may be significant as our review has shown the relationships between microbes and diseases. When the homeostasis of gut-microbes is disrupted, multiple mechanisms have been shown to contribute to diseases' development. The balance between protective and pathogenic microbes must be kept in check to prevent disease onset. With a better understanding of this relationship, we will investigate the potential methods to modify the gut flora as the background of developing therapeutic options. There are already some therapeutic options such as prebiotics, probiotics, and fecal transplantation, but their clinical use is limited and restricted. Therefore, there is still a need to investigate the characteristic microbiome association with gut-dysbiosis-related diseases, which may help manage the disease and develop diagnostic and monitoring tools. This review aims to discuss our gut microbiome and its association with human health and diseases.
\end{abstract}

Keywords: Microbes, gut microbiome, homeostasis, gut-dysbiosis, diseases. 


\section{Introduction}

It has been a chaotic start to the New Year 2021, with a rising number of Covid-19 cases worldwide ${ }^{[1-4]}$. People are still suffering from this disease, exhibiting asymptomatic to severe symptoms, and losing their loved ones to the disease ${ }^{[5-7]}$. The Covid-19 pandemic has brought in many changes to our daily and professional life. People around the globe adopted the "new norm" - together, we fight against this virus. These days homes are our new offices - where everything is held virtually, and our social life has all been altered. The work from home concept has brought new challenges to our professional, personal, and family life. In whatever circumstances, we should always devote our time to a healthy lifestyle and fitness.

Foremost, we should understand our body before we step into changing our life. A range of microorganisms colonizes our body, comprising bacteria, viruses, eukaryotic, and archaea, collectively forming the microbiome community ${ }^{[8]}$. It is a vast active population consisting of nearly 100 trillion microbes and weighing as heavy as our human brain ${ }^{[9]}$. Every organ has distinct microbial communities that vary in composition and function, with its aggregate function and metabolic capacity ${ }^{[8]}$. They live in a symbiotic relationship with the host and responsible for various roles, including protecting against pathogens, digestion of nutrients, and metabolism of drugs and substances ${ }^{[10]}$. These microbiotas are incredibly dynamic. They continuously fluctuate around a set point and vary from site to site ${ }^{[11,12]}$. Also, the composition of the microbiome is determined by multiple environmental and local factors. For instance, the organ site's $\mathrm{pH}$ and substrate determine microbes suitable for surviving and living in the community ${ }^{[13,14]}$.

Among the different microbiomes on different human body sites, the gastrointestinal tract has the most affluent microbes' community. So, what makes a good gut microbiome community and how they play in health and diseases. There are hundreds to thousands of distinct bacterial species in our gut, some can be beneficial or pathogenic. The Bacteroidetes and Firmicutes phyla dominates the main pool of community in the gut ${ }^{[13]}$. Our healthy gut microbiome produces short-chain fatty acids (SCFA), which is crucial in regulating the gut's functional and structural integrity ${ }^{[15,16]}$. The gut community plays a vital role in developing gastrointestinal mucosal immunity, an essential part of our immune defense system ${ }^{\text {[17-19]. }}$. Any disruption of this balanced ecosystem has been influenced and implicated by the gut microbiome. These include cancer, autoimmune disorders, inflammatory bowel disorders, diabetes, psoriasis, eczema, asthma, and autistic spectrum disorder (ASD) ${ }^{[20-27]}$.

The evidence is mounting on gut microbiome association in health and diseases. Our biologists are exploring and studying the gut ecosystem, in order to prevent the development of diseases. There is an growing interest in potential novel treatments, preventive and diagnostic methods for the diseases using homeostasis of the gut microbiome as the stepping stone ${ }^{[28,29]}$. This review aims to discuss human health, particularly examining the association between the gut microbiome and health and diseases (Figure 1). 


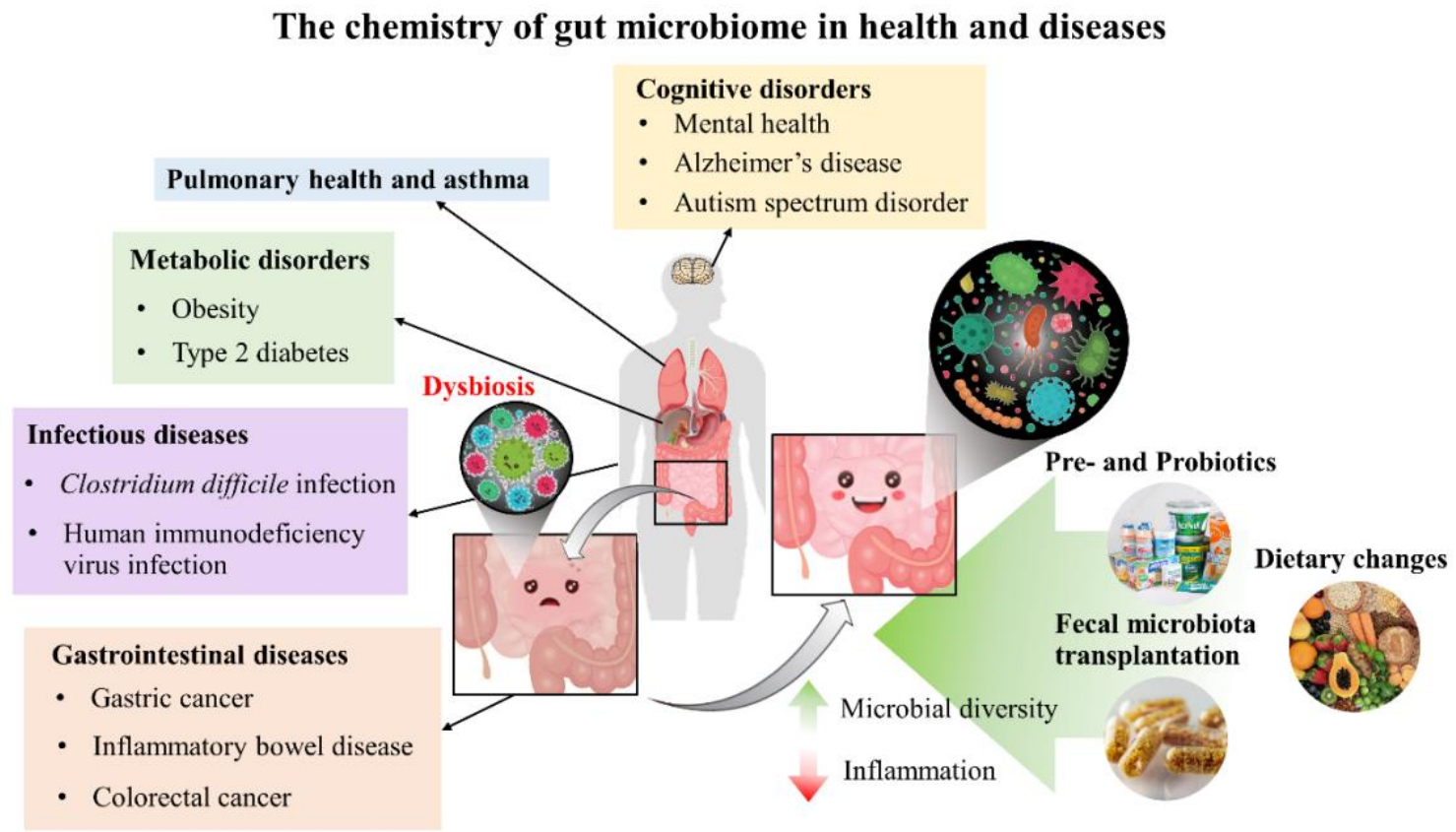

Figure 1. The association of gut microbiome with health and disease. Probiotics, prebiotics, dietary changes, and fecal transplantation are potential or current therapeutic options for gut-dysbiosis associated diseases.

\section{Origins of our gut microbiome}

We have always thought humans are born with sterile guts, not until recent contradicting evidence supporting in-utero transmission of microbes ${ }^{[30]}$. The advancement of genetic sequencing has given us the privilege to investigate the microorganisms in maternal tissues better than before ${ }^{[31]}$. Studies of the meconium microbiome have enabled us to understand that gut colonization occurs before birth ${ }^{[32]}$. This is evident by the similarity in meconium microbiota among newborns even if delivered via different methods (vaginal delivery and cesarean delivery) ${ }^{[33]}$. Also, the endometrium and placenta are not wholly sterile ${ }^{[34]}$. They may act as possible sources for gut colonization to occur in the fetus. However, it is still unclear how and when exactly colonization of the fetus' gut occurs. Meanwhile, ingestion of amniotic fluid has been suggested as one of the possible routes ${ }^{[35]}$.

When the infant is being delivered, the process allows colonization of the microbiome to occur. Thus, arises the controversy of whether the mode of delivery can affect human microbiota. Newborns delivered via cesarean section instead of vaginal delivery have been observed to lack the composition of maternal vaginal and fecal bacteria (e.g., Lactobacillus and Prevotella) ${ }^{[36]}$. However, recent studies have shown that by two months of age, the delivery mode subsides effects. Other confounders may cause the discrepancy of gut flora between infants delivered vaginally or via cesarean section ${ }^{[37,38]}$. For instance, maternal comorbidities are implicated in cesarean delivery and lower exclusive breastfeeding rates in this group of mothers ${ }^{[39]}$. Interesting to know that breastfed infants have a lower diversity of gut flora before six months of age than their non-exclusively breastfed counterparts. 
However, exclusively breastfed seems to be a protective factor against bowel diseases ${ }^{[40]}$. Thus, the author postulates that a less diverse gut microbiome may be required for the first few months to develop a healthy gut ${ }^{[40]}$. Perhaps, more studies are needed to investigate the significance of differences in gut microbiome between these two groups of infants.

Infants will gradually build up their unique microbiome via exposure to many factors ${ }^{[8]}$. Biological and environmental factors can all leave footprints on the composition of the human microbiome ${ }^{[41]}$. When infants start a solid diet around six months of age, the initial diversity gut microbiome begins flourishing with different microbes. This diet contributes to forming a complex and diversifying gut microbiome, which achieves its stability at around three years of age ${ }^{[31,42]}$. Besides, a study has shown that our diet can affect our gut microbiome ${ }^{[43,44]}$. For instance, a high fiber diet has increased Bacteroidales and Firmicutes ${ }^{[45]}$ population, potentially commensal to a healthy gut. However, as part of aging, dysbiosis of the gut could occur ${ }^{[46]}$. Aging is a physiological process associated with diminished gut microbiome diversity and slowly weakened gut functional integrity ${ }^{[46]}$.

Today, our dependency on antibiotics has played a vital role in forming our gut diversity and community. Dethlefsen and Relman's study revealed an alteration of the gut community after using ciprofloxacin for 3 to 4 days ${ }^{[47]}$. However, despite the gut microbiome's tendency to shift back to its initial composition, the recovery was observed to be incomplete ${ }^{[47]}$. Thus, the effect of repeated or long-term use of antibiotics on gut flora remains unknown. Further research is required to understand the role of antibiotics in gut dysbiosis completely.

\section{Gut microbes and diseases}

In the early days, people believe in Galenism, which explains diseases resulting from an imbalance in bodily fluids or humor ${ }^{[48]}$. Not until the $16^{\text {th }}$ century, with the development of a microscope, the model by Parcelsians which regards tiny inorganic particles as the culprit of diseases are justified ${ }^{[48]}$. However, this exciting concept submerged for decades until Louis Pasteur and Robert Koch successfully demonstrated germ theory's validity. They proved that microorganisms could be the causative agents of diseases ${ }^{[49]}$.

Scientists have observed the symbiotic relationship between the host-microbe system in fecal and oral microbiota ${ }^{[8]}$. In addition, environmental microbes have been seen to live in an involved community ${ }^{[50]}$. Human microbes are a community of microorganisms that interact with one another and the host so delicately that its disruption may lead to various health diseases and mental health disorders. There are blooming studies on the association between human microbes and many diseases. These studies have demonstrated gut

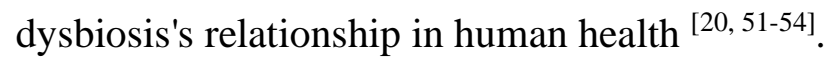

\subsection{Gastrointestinal diseases}

\subsubsection{Inflammatory bowel diseases}


Inflammatory bowel disease (IBD) is the chronic inflammation of the gastrointestinal tract, consisting of ulcerative colitis and Crohn's disease. The pro-inflammatory state in IBD can be attributed to the dysregulated host's inflammatory response in genetically susceptible individuals towards the gut microbiome ${ }^{[55]}$. The environmental factors are then responsible for the disease's onset and recurrences ${ }^{[56,57]}$.

When comparing the gut microbiota of individuals with IBD and healthy counterparts, there is a significant discrepancy between them ${ }^{[58-60]}$. It is observed that individuals with IBD have a higher population of pro-inflammatory microbes (Proteobacteria, Escherichia spp., Fusobacterium spp.) and a lower population of protective microbes (Bacteroidetes, Firmicutes, butyrate-producing spp.) ${ }^{[40,61,62]}$. By reducing butyrate-producing species responsible for short-chain fatty acids (SCFA) production, it is not surprising that individuals with IBD have a lower concentration of these molecules ${ }^{[63]}$. The significance of lacking these molecules and reduced population of protective microbes ${ }^{[64]}$ is that they have been shown to play an anti-inflammatory role in immune responses. The deficit in these microbes can lead to a pro-inflammatory state, parallel with the disease state in individuals with IBD.

When discussing the differences between the gut microbiome of IBD individuals and healthy counterparts, it is unsure whether it is a cause of the disease or its result. However, recent studies have been able to show that genetic factors such as nucleotide oligomerization domain (NOD 2), caspase recruitment domain-containing protein 9 (CARD 9), and autophagy-related 16-like 1 (ATG16L1) ${ }^{[65-67]}$ may be attributed to the differences. The expression of these genes is responsible for the anti-inflammatory and antimicrobial effect in the gastrointestinal tract. Besides, they also help to regulate the homeostasis of the gut microbiome by determining its composition. Studies revealed that Nod-2 deficient mice have a higher gut commensal population and a higher vulnerability to be colonized by pathogenic microbes ${ }^{[68,69]}$.

On the other hand, ATG16L1 mice have been observed to have a higher Bacteroides species population with an anti-inflammatory role ${ }^{[70]}$. Thus, altering this gene expression can disrupt the gut's colonization and its inflammatory response and defense against pathogens. When extrapolating this to the human host, it explains the vulnerability of genetically susceptible individuals to disruption of gut homeostasis, leading to inflammatory bowel disease ${ }^{[71]}$.

The terminal ileum is the most affected segment of the gut in Crohn's disease and the colon segment in ulcerative colitis. This corresponds to the gastrointestinal tract sites in individuals with IBD with a higher microbes concentration than healthy individuals ${ }^{[72]}$. The parallel distribution of microbes and affected gut segments in IBD illustrates the effect of gut dysbiosis in the disease activity of IBD. Moreover, mice that have received fecal microbiome from mice with colitis have been observed to develop colitis ${ }^{[73]}$. Besides that, improvement of IBD symptoms by using antibiotics, probiotics, and fecal transplantation, suggest that 
dysbiosis of gut flora contributes to the pathogenesis of the disease ${ }^{[74]}$. The disease activity of IBD is correlated to the biodiversity of the gut microbiome ${ }^{[75]}$. They have half the gut microbiome's diversity compared to healthy individuals ${ }^{[76]}$.

Interestingly, Swidsinski et al. have identified the characteristic spatial composition of fecal flora in Crohn's and ulcerative colitis ${ }^{[77]}$. The difference in abundance of mucosaassociated or fecal Faecalibacterium prausnitzii can be potentially used as a biomarker to differentiate between the two diseases ${ }^{[78]}$. It is observed that Crohn's disease has depleted $F$. prausnitzii with normal leukocyte count. In contrast, ulcerative colitis has a higher abundance of $F$. prausnitzii with increased leukocytes in the fecal mucus transition zone ${ }^{\text {[7]] }}$. However, compared to healthy individuals, individuals with IBD have less diversity in subtypes of $F$. prausnitzii, and there is a shift in the phylotype distribution of $F$. prausnitzii species ${ }^{[79]}$. Some $F$. prausnitzii subtypes are disease-specific, allowing discrimination between individuals with IBD and healthy counterparts ${ }^{[79]}$. Perhaps we may consider analyzing punched fecal cylinders obtained from individuals with IBD to diagnose and monitor the disease, given the characteristic composition and spatial distribution of gut microbes in individuals with IBD $[77,78]$.

\subsubsection{Gastrointestinal malignancies}

\section{a) Colorectal cancer}

Colorectal cancer is one of the most common forms of cancer that affects both genders ${ }^{[80]}$. It is known that chemoresistance is a hurdle in colon cancer therapies. Hence, there is an interest to study the anti-colon cancer potential of novel streptomycetes as an effective treatment for colon cancer ${ }^{[81-85]}$. Recently, studies revealed the role of colon microbes in the carcinogenesis of colorectal cancer ${ }^{[69]}$. These studies' evidence is supported by the positive correlation between microbes' concentration and cancer cells' distribution. Cancers have been linked with our immune and genetic dysregulation. The gut microbes are known to involve themselves in cancer development by altering the gut into pro-inflammatory and procarcinogenic states. Some of the microbes can act as 'bacteria drivers' which damage the gut epithelial DNA. This can lead to hyperproliferative epithelial cells, the cells' ability to evade apoptosis, and so on, which are the cancer hallmarks ${ }^{[86,87]}$. Besides, the 'bacteria drivers' can disrupt the gut integrity, favoring the proliferation of pathogenic 'passenger microbes', which plays a synergistic effect with the 'bacteria driver' ${ }^{\text {' }}{ }^{66,87]}$. Wu et al. have shown specific gut commensal mechanisms in activating the host's immune system, creating a favorable proinflammatory state for cancer development ${ }^{[88]}$. This may be postulated as the disruption of gut homeostasis, allowing the overgrowth of pathogenic commensal, leading to the development of colorectal cancer. 
Fusobacterium nucleatum is a causative effect in the development of colorectal cancer [89, 90]. This microbe has been observed to have a negative relationship with the number of CD3+ T cells in individuals with CRC ${ }^{[89,91]}$. They can bind via the bacteria-derived protein Fap2 on exclusively human T cell immunoglobulin and ITIM domain (TIGIT) molecules thus inhibiting natural killer cells in removing cancer cells ${ }^{[89]}$. This evades the tumour suppression process, thus contributing to the development of tumors ${ }^{[89]}$. Also, F. nucleatum spp. can recruit $\mathrm{CD} 11 \mathrm{~b}+$ to promote a pro-inflammatory and oncogenic environment, which further supports its virulence in causing CRC ${ }^{[92,93]}$. Interesting to note that, with the use of metronidazole, mice study has shown that the population of $F$. nucleatum is reduced and the retarded tumor growth and proliferation of cancer cell. Perhaps further investigation down this path can allow for the potential use of antimicrobial in managing colorectal cancer ${ }^{[90]}$.

There is also a discrepancy between the gut microbiome in individuals with colorectal cancer and healthy individuals. Individuals with colorectal cancer have higher population of Streptococcus bovis ${ }^{[94]}$, Bacteroides fragilis ${ }^{[95,96]}$, Clostridium septicum ${ }^{[97]}$, Fusobacterium spp. ${ }^{[92]}$, Enterococcus faecalis ${ }^{[98]}$ and Escherichia coli ${ }^{[99]}$. Studies have observed that these microbes are associated with carcinogenesis via different virulence factors ${ }^{[96,100,101]}$. They can alter host metabolism, immune system, and production of genotoxins, which can align the gut environment towards pro-carcinogenic state ${ }^{[102]}$. Arthur et al. have shown the mechanisms of virulence factors and metabolites of certain microbes in the progression of colorectal cancer ${ }^{[103,104]}$. This further supports that the gut microbes do play a vital role in developing colorectal cancer, and more research is needed to identify the exact microbiota associated with the disease.

In addition, recent studies have shown that microbes can form biofilms that can hold them together forming a shield against external agents ${ }^{[105]}$. They proliferate within the biofilms and damaging the E-cadherin in the colon ${ }^{[106]}$. This increases intestinal permeability, activates the local inflammatory response, and induces gut dysbiosis ${ }^{[106]}$. This has been seen in mice studies in which biofilms formation has been an imperative factor in promoting the oncogenic potential of microbiome in CRC development ${ }^{[107,108]}$.

Meta-analysis studies have shown an increase in protein, choline, and mucin ${ }^{[109,110]}$. Moreover, it is associated with the enhanced fermentation process, gluconeogenesis, and secondary bile acids production with reduced carbohydrate metabolism ${ }^{[109,110]}$. This portrays a shift from the microbiome that utilizes carbohydrate metabolism in healthy gut to use amino acids and fats. Furthermore, individuals with CRC have a higher concentration of amino acids in the feces and gastrointestinal epithelium, suggesting the association between meat-rich high-fat diets with colorectal cancer ${ }^{[109,110]}$. This is plausible as diet is known to be one of the factors that can modify the gut microbiome ${ }^{[92,93]}$, which influences our health. 


\section{b) Gastric cancer}

With the emergence of Louis Pasteur and Robert Koch's germ theory, there is a bloom in research on the microbiome's role in diseases. In the late $19^{\text {th }}$ century, the relationship between gastric microbes and gastric cancer is proposed despite the fact that the gastric organism's predominant organism is yet to be identified [111]. This was later denied by Heinemann and Ecker, who observed that the microbes suggested by the previous study were Lactobacillus. Reduction in gastric acidity has allowed the proliferation of this species, and it is not causative of gastric cancer ${ }^{[112]}$. It is not until the late $19^{\text {th }}$ century, with the discovery of Helicobacter pylori, researchers begin to relate the association between gut microbiome with gastric cancer ${ }^{[113]}$.

The $H$. pylori affect approximately $50 \%$ to $60 \%$ of the world's population ${ }^{[114,115]}$. It is known to cause gastric cancer in $1-3 \%$ of those with $H$. pylori infection ${ }^{[116]}$ and contributes to around three-quarters of all gastric cancer cases ${ }^{[117]}$. They are multiple strains of $H$. pylori, and each possesses different virulence factors that can cause genetic mutation, thus interfering with gastric epithelial cellular division, function, and immune responses ${ }^{[118,119]}$. One of the proposed mechanisms is that $H$. pylori can produce reactive oxygen species that can lead to DNA mutations, aberrant methylation, and oxidative damage, leading to loss of functioning tumor suppressor genes ${ }^{[120]}$. Another virulence factor worth noting is the CagA protein. CagA is associated with a higher risk of premalignant and malignant gastric lesions [121]. The H. pylori utilize its adhesion molecules for prolonged colonization of gastric epithelium and injecting its oncogenic proteins, including CagA, into the gastric epithelial cells. This oncogenic protein then leads to alteration of the morphology of epithelial cells and disrupts the epithelial intercellular junction. In addition, these molecules trigger metaplasia and dysplasia of the epithelial lining which leads to the development of gastric cancer ${ }^{[122-}$ 124].

The H. pylori possess vacA toxin, which can disrupt the mitochondrial membranes, creating vacuoles in the cytoplasm, causing apoptosis of the gastric epithelium. This is aligned with the mechanism of $H$. pylori-related atrophic gastritis, which subsequently undergoes metaplasia and dysplasia of the epithelium, leading to the development of gastric cancer ${ }^{[120]}$. Moreover, these virulence factors promote inflammation and create an environment favorable for tumorigenesis ${ }^{[118,125]}$. The disrupted gut epithelial cells will begin to increase uncontrollably, leading to gastric cancer. Saenz et al. have proposed that gastric epithelium can respond to injury by cellular plasticity and reprogramming. However, the mechanism of dedifferentiation and differentiation is vulnerable to the accumulation of genetic mutations, which can further predispose the host to gastric cancer ${ }^{[126]}$. This is supported by the stem cell-like cells observed in the transition of epithelial to mesenchymal cells in the process of transitioning to gastric malignancy ${ }^{[127]}$. 
Besides $H$. pylori, other microbes may also contribute to gastric cancer development with or without the aid of $H$. pylori infection. When observing individuals with $H$. pylori infection's gut microbiome, they have a higher proportion of Actinobacteria, Firmicutes, and Bacteroidetes. ${ }^{[128]}$. This discrepancy is significant because Bacteroidetes has been shown to promote gastric cancer in genetically predisposed germ-free mice to a similar extent as genetically predisposed specific pathogen-free mice ${ }^{[129]}$. This indicates that microbes can play a part in carcinogenesis. Gen genetically predisposed specific pathogen-free mice to appear to have more severe and vigorous gastric cancer progression than genetically predisposed germ-free mice ${ }^{[130]}$.This illustrates that $H$. pylori can alter the gut microbiome by disrupting commensal, which confer protection and promotes pathogens' growth, enhancing its carcinogenic effect. It also shows that pathogenic microbes can alter the gut microbiome into a pro-carcinogenic environment that can favour more severe disease development. Fortunately, with the availability of treatment option for $H$. pylori infection, we can eradication this pathogen before it causes detrimental harm to our body.

\subsection{Infectious diseases}

\subsubsection{Clostridium difficile infection}

Clostridium difficile infection beautifully demonstrates gut dysbiosis as the pathogenesis of the disease. The infection is due to pathological overgrowth of an organism following antibiotic use ${ }^{[131]}$. C. difficile is part of the gut flora, and its population is regulated by the homeostasis of the gut microbiome ${ }^{[131]}$. Antibiotics are used to disrupt this equilibrium, reduce microbe diversity, and cause a significant shift in composition ${ }^{[131,132]}$. Gu et al. have shown that antibiotic use is associated with a diminished number of putative butyrateproducing anaerobes and increased endotoxin-producing opportunistic pathogens ${ }^{[131]}$. This may explain the opportunistic overgrowth of $C$. difficile in patients with recent antibiotic use.

The $C$. difficile infection is caused by the toxin released by the microbes following germination of the $C$. difficile spores ${ }^{[133,134]}$ and bile acids are critical for the germination of these spores. The liver produces bile acids that are secreted into the gastrointestinal tract. Some of these acids tracked down the colon, which is subsequently bio-transformed by the gut flora into secondary bile acids ${ }^{[135,136]}$. The biotransformation happens via the catalyst activity of $7 \alpha$-dehydroxylation and some other enzymes $[134,135]$. This balance may be disrupted by the use of antibiotics, which results in the accumulation of primary bile acids (cholic acid, chenodeoxycholic acid) and reduction in secondary bile acids (deoxycholic acid, lithocholic acid), thus favoring the germination of $C$. difficile spores ${ }^{[137]}$.

Kang et al. have reported that some of the commensal possessing bile acid $7 \alpha-$ dehydroxylating property, for instance, Clostridium scindens and Clostridium sordellii can inhibit the in vivo growth of $C$. difficile ${ }^{[135]}$. They secrete tryptophan derived endogenous antibiotics to outcompete other microbes in the complex gut ecosystem ${ }^{[135]}$. Interestingly, the secondary bile acids produced by the $7 \alpha$-dehydroxylating bacteria themself can further 
enhance the endogenous antimicrobial effect ${ }^{[135]}$. Thus, any disruption in this regulating mechanism of the gut will reduce the protective microbes' population, which favors the growth of $C$. difficile.

\subsubsection{Human immunodeficiency virus infection}

Human immunodeficiency virus (HIV) is an on-going global public health issue. With the development of highly active anti-retroviral therapy (HAART), the incidence of acquired immunodeficiency syndrome (AIDS) has significantly reduced. Mortality of HIV has dropped tremendously from $80 \%$ to $50 \%$ within ten years since its discovery ${ }^{[138]}$. However, HAART treatment does not seem to revert the chronic inflammatory status in individuals with HIV [139]. This pro-inflammatory state in HIV individuals has been shown to drive the disease progression ${ }^{[140,141]}$, on top of its associated high morbidity and mortality ${ }^{[142,143]}$

Researchers investigated the chronic inflammatory state's etiology in individuals with HIV, including individuals treated with HAART with undetectable viral load. They noticed a massive reduction of CD4 $\mathrm{T}$ cells in the gut, especially those responsible for enhancing gut

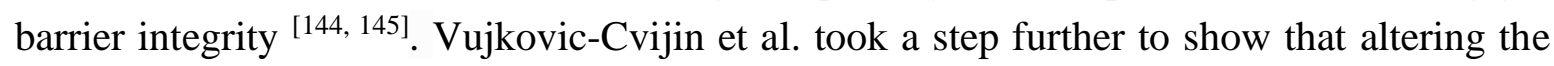
gut immune system in HIV individuals can be linked to disruption of the gut microbiome with its associated local inflammation ${ }^{[146]}$. It is still inconclusive on the findings regarding the shift of gut microbiome in individuals with HIV. There is a consensus on reducing gut microbiome diversity, but the gut microbiome's specific signature in individuals with HIV is yet to be identified ${ }^{[147-149]}$. Some common findings include the increase in Prevotella spp. and decrease in a decrease in Bacteroides spp.

These microbes are proposed to have different gut immunology roles, and the alteration in their abundance can affect gut diversity. For instance, Prevotella spp. can create an inflammatory response by activating myeloid dendritic cells, colonic $\mathrm{T}$ cells, expression of CD40, and some other inflammatory mediators ${ }^{[147]}$. Meanwhile, the Bacteroides spp. is responsible for protecting gut health by expression polysaccharide-A (PSA). This molecule inhibits the activation of Th17, which is a subset of CD $4+$ T cells ${ }^{[150,151]}$. The species also stimulates the invariant natural killer $\mathrm{T}$ in the gut-associated lymphoid tissue ${ }^{\text {[152-154]. }}$ Together with the Th17 cells, they are responsible for controlling the gut microbiome's homeostasis and regulating the microbiome's translocation. Reduction in Th17 cells indicates the loss of security of the gut barrier, in which the tight intercellular junctions are disrupted, thus allowing gut microbes to enter the systemic circulation. This creates a persistent inflammatory state in individuals with HIV ${ }^{[155,156]}$, even under HAART treatment ${ }^{[151,157]}$.

When isolating the fecal microbiome from individuals with HIV individuals, it is observed to have higher levels of activated $\mathrm{T}$ cells and monocytes, which is positively correlated with the host's viral load ${ }^{[158]}$. Even in individuals receiving antiretroviral therapy (ART), there is still activation of adaptive immunity despite a lesser extent than individuals not receiving HRT ${ }^{[158]}$. Neff et al. also suggested that tumor necrosis factor $\alpha$ and Toll-like 
receptor-2 are the immune mediators that activate the inflammatory response in individuals with HIV. Besides the 'leaky' gut hypothesis, the gut microbiome's pro-inflammatory properties in HIV individuals can lead to a chronic inflammatory state ${ }^{[158]}$. There are still gaps to be filled in terms of the gut microbes' involvement in the progression of HIV disease so that adjuvant therapies that may restore gut homeostasis can be developed ${ }^{[159]}$, thus reducing HIV- associated morbidity and mortality.

\subsection{Metabolic disorders}

\subsubsection{Obesity}

Microbes have many potential roles in our gut, ranging from digestion, regulation of absorption to metabolism of drugs and substances. They can also synthesize molecules such as short-chain fatty acids, affecting our immune and metabolic systems ${ }^{[160]}$. Unsurprisingly obesity is part of metabolic disorders ${ }^{[161]}$. The disruption of gut homeostasis can affect the balance energy uptake from diet and its expenditure ${ }^{[162]}$. This can be explained by the role of microbes in nutrient handling. They can break down indigestible diet and convert them into short-chain fatty acids (SCFA), for instance, acetate, butyrate, and propionate. These substances are then involved in different functions and activities in various organs.

Butyrate, acetate, and propionate are required to produce glucose and lipids in the liver ${ }^{[163]}$. They stimulate the enteroendocrine L cells to release glucagon-like neuropeptided-1 and release local factor peptide YY, regulating lipid digestion and lipid metabolism on top of deposition of fatty acids in the liver. Meanwhile, butyrate also acts as a significant energy source for the colon's epithelial cells ${ }^{[163]}$. The concentration of these end products is dependent on the gut flora of the host as different gut microbiome are associated with varying properties of metabolism. Turnbaugh et al. have shown that genetically obese mice have higher acetate and butyrate levels in the gastrointestinal tract and lower energy content in their feces than genetically lean mice ${ }^{[164]}$. This illustrates that the gut community in genetically obese mice are better in energy extraction than their lean counterparts. On the other hand, some of these SCFA end products can have a beneficial effect on health. For instance, butyrate and propionate have been seen to enhance satiety ${ }^{[148,149]}$. Furthermore, butyrate enhances mitochondrial function and oxidation of fats, increasing the energy expenditure ${ }^{[101]}$. Thus, it is reasonable to suggest that different gut microbiome compositions can have other metabolic effects that can affect the hosts' metabolic profile.

It is also observed that obese host has reduced gut microbes biodiversity ${ }^{[164]}$ and higher Firmicutes to Bacteroidetes ratio versus healthy individuals $[165,166]$. The Firmicutes are associated with the production of SCFA and utilized in lipogenesis [167]. Interestingly, this discrepancy in Firmicutes to Bacteroidetes ratio can be reversed via weight loss demonstrated in mice studies ${ }^{[168]}$ and in individuals who have undergone bariatric surgery ${ }^{[169,170]}$. This characteristic of gut microbiota and its reversibility illustrate that specific microbe are more favorable to a specific metabolic phenotype in nutrient handling and metabolism. Meanwhile, 
Bacteroidetes are responsible for the breakdown of branched-chain amino acids (BCAAs) which are strongly associated with obesity ${ }^{[171]}$. Thus, reduction of the species in obese individuals can explain the higher circulating levels of BCAAs ${ }^{[171]}$, which results in hyperphagia ${ }^{[172]}$. However, other study results on the composition of the obesity-related gut microbiome are contradicting. To date, the data is still inconclusive on the exact composition of the obesity-related gut microbiome, other than the common findings on reduced diversity of gut flora in obese individuals ${ }^{[165]}$.

Even so, animal studies on gut microbes and obesity are still quite promising. When fecal microbes from obese or lean twins were transplanted to germ-free mice, they showed similar metabolic phenotypes and adiposity as their host-source ${ }^{[173]}$. When microbes from lean cotwins were transplanted to obese mice fed with a regular diet, they successfully prevented the obese mice from further gaining adipose tissue source ${ }^{[173]}$. This illustrates the possibility of transmitting the lean and obese phenotype by transplantation of gut microbes and the influence of different gut microbiome ecosystems on individuals' metabolic profile. Furthermore, microbes play a significant role in energy harvesting, which can impact the host's metabolic profile. It is observed that transplanting gut microbes from conventionally raised mice to germ-free mice can cause significant gain in body fat despite reduced food consumption ${ }^{[174]}$. This can be explained by microorganisms' ability to ferment indigestible dietary carbohydrates, which can then be absorbed and converted into lipids ${ }^{[174]}$. These lipids are then further promoted to be stored as adipose tissues ${ }^{[174,175]}$. This can be extrapolated on obese individuals such that they may possess characteristic gut microbiota that has enhanced efficacy in extracting energy from the diet, thus contributing to their excess storage.

\subsubsection{Type 2 diabetes}

Type 2 diabetes (T2DM) is a chronic disease characterized by increased blood sugar level, relative insulin deficit, and insulin resistance ${ }^{[26,176]}$. It is also associated with other metabolic abnormalities such as incretin deficiency, raised glucagon level, and increased lipids breakdown ${ }^{[177,178]}$. T2DM, as with other chronic diseases, has been attributed to gut dysbiosis. This has been illustrated by Backhead et al. in which different gut microbiota has demonstrated different glucose metabolism profile, even when the mice are of similar genotype and controlled for their diet pattern ${ }^{[174]}$. This shows that a diverse gut microbiome with different glucose metabolism capabilities and lower glucose metabolism can predispose the host to T2DM.

It is also long known that T2DM is associated with low-grade systemic inflammation, which leads to insulin resistance of the host ${ }^{[179]}$. This pro-inflammatory state can be led back to the host's microbiome which can play a role in metabolism and immunology. As in other chronic diseases, reducing gut microbial diversity has been observed in individuals with T2DM [180]. This allows the overgrowth of pathogenic microbes to promote local inflammation by activating innate immunity ${ }^{[180]}$. The inflammatory mediators from the 
immune response or microbes' toxins disrupt the intestinal barrier, allowing gut content, including microbes, to enter the systemic circulation ${ }^{[180]}$. The immune system is then activated by the bacteria and toxin in the blood, which creates a low-grade systemic inflammation that is pro-insulin resistant ${ }^{[180]}$.

Overall, Gurung et al. have reported a consistent increase in Fusobacterium, Ruminococcus, and Blautia genera, decreasing Bacteroides, Bifidobacterium Akkermansia, Faecalibacterium, and Roseburia genera in individuals with T2DM [181]. Among these protective microbes, Bifidobacterium genus is the strongest protective factor against T2DM ${ }^{[182,183]}$. Animal studies have successfully demonstrated the reduction in blood glucose level when introduced to Bifidobacterium spp. ${ }^{[184,185]}$. Also, losing these protective gut microbes can contribute to the chronic inflammatory state in T2DM individuals. These protective microbes can inhibit pro-inflammatory mediators. For instances, TNF- $\alpha$, IL-8,IL-1 $\beta$, CD36, Monocyte Chemoattractant Protein-1, Intercellular adhesion molecule-1, and C-reactive protein ${ }^{[186,187]}$. Other butyrate-producing microbes also produce metabolites that suppress NF-kB ${ }^{[188]}$. Without them, it is not surprising that the inflammatory pathway will be dominant, which causes chronic inflammation in the host. Interesting to note that individuals with T2DM have a lower population of Roseburia spp. ${ }^{[189]}$. The Roseburia spp. has been inversely associated with the plasma glucose level in individuals with T2DM ${ }^{[190]}$. This shows that different microbes have different metabolic properties, which may either confer towards or against the disease activity of T2DM.

As discussed, some gut commensal, especially Clostridium spp. is involved in converting primary into secondary bile acids ${ }^{[191]}$. These bile acids can then affect glucose metabolism by activating membrane-bound, G-protein-coupled receptor TGR 5 and nuclear farnesoid X receptor (FXR). These receptors can be activated to inhibit the enzymes involved in gluconeogenesis ${ }^{[192]}$. Also, TGR 5 membrane receptor on the enteroendocrine L cells has been suggested to increase the secretion of glucagon-like peptide- 1 (GLP-1). GLP-1 is an incretin hormone that enhances the insulin effect and increases satiety ${ }^{[193]}$. On the other hand, FXR is shown to improve glucose tolerance and increase insulin sensitivity ${ }^{[191]}$. Thus, gut dysbiosis that interferes with bile acids' biotransformation can have a ripple effect on glucose metabolism and glucose level regulation, thus contributing to T2DM.

In addition, it is known that the gut microbiome can metabolize nutrients into SCFAs [194]. Most of these end products are then absorbed and utilized by the host for various functions ${ }^{[194]}$. The SCFAs include butyrate and propionate, beneficial to the host's energy balance and metabolism ${ }^{[194]}$. For example, propionate stimulates GLP-1 and peptide YY secretion, which reduces energy intake ${ }^{[195]}$. Sanna et al. have shown that the gut microbiome that produces butyrate can enhance beta cells' function. In contrast, those with reduced propionate absorption can confer an increased risk of T2DM ${ }^{[194]}$. In short, various mechanisms can implicate the development of T2DM, and maintenance of the homeostasis of gut flora is the key to prevention. 


\subsection{Pulmonary health and asthma}

The lower airways were once thought to be sterile until recent years; studies have demonstrated microbes in the lungs, even in healthy individuals ${ }^{[196,197]}$. Lungs microbes are detectable right after birth ${ }^{[198]}$, and their composition is enriched by the upper airway ${ }^{[199]}$ and oropharyngeal microbes ${ }^{[200]}$. The gut-lung axis concept was also suggested in parallel to the increased attention given to the correlation between human microbes and diseases. This has been demonstrated by Schuijt et al., in which gut microbes depleted mice have a more disseminated disease, complications, and higher mortality when infected with Streptococcus

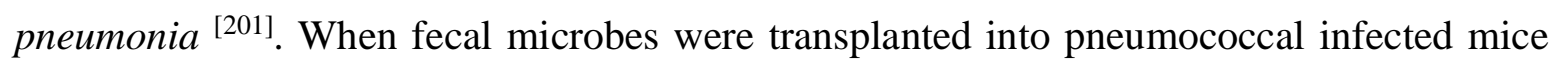
with depleted gut microbes, the lungs' inflammatory response was reduced ${ }^{[201]}$. This shows that gut microbiota can enhance host defense against lung infection.

Asthma is an atopy related respiratory disease characterized by chronic inflammation of the smaller airways ${ }^{[202]}$. When comparing the microbiome of asthmatic to healthy individuals, it is found that asthmatic patients have a higher population and diversity of microbes ${ }^{[197,203]}$. The colonization of an infant's oropharyngeal by Moraxella, Haemophilus, and Streptococcus before one year of age has been shown to predict the risk of developing asthma later on ${ }^{[204]}$. While moving to the comparison of the gut microbiome, a study showed a reduction in the population of genera Faecalibacterium, Lachnospira, Veillonella and Rothia in infants with increased risk of developing asthma in the first hundred days of life

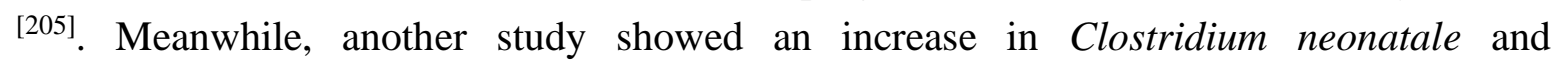
Lachnospira in the infant's gut flora, which is predictive of asthma risk at the pre-school age [206].

Recently, there is increased research on the gut-lung axis concept, a bi-directional relationship between the gut and the lungs [207]. They are proposed to be involved in regulating a 'common mucosal immunological system' ${ }^{[208]}$. There is increasing evidence that one mucosal compartment's inflammation can impact the distal mucosal site ${ }^{[208]}$. This is in line with the dysbiosis of both lungs and gut microbiome observed in individuals with asthma. In addition, childhood use of broad-spectrum antibiotics has also been associated with increased asthma development later ${ }^{[209,210]}$. This further illustrates that disruption of the homeostasis of the gut microbiome can affect the lungs' immunity. However, the exact mechanism is still unknown, and more studies are needed to understand this mucosal immunological system and the bi-directional relationship between compartments ${ }^{[208]}$. If it is indeed evident, the concept can be beneficial in explaining various diseases, including asthma, associated with airway mucosa inflammation.

Besides that, the composition of the lung microbiome is related to its treatment responsiveness. Corticosteroid-resistant patients are populated by Proteobacteria (Haemophilus, Neisseria), which produces endotoxin triggering chronic inflammation ${ }^{[211]}$. In contrast, Fusobacterium and Bradyrhizobium, which have lower endotoxicity, were found 
in treatment sensitive patients ${ }^{[211]}$. Moreover, the severity can also influence the gut flora's alignment with the gut-lung axis concept. Bisgaard et al. demonstrated that the gut microbiome could be modified by viruses ${ }^{[212]}$. This allows the overgrowth of specific pathogens that are associated with severe asthma. There are evidence implying a high fiber diet can reduce asthmatic symptoms by modifying the gut microbiome's composition ${ }^{[213]}$. It is shown that gut microbes can ferment soluble high fiber diets to produce short-chain fatty acids with an immunomodulatory effect ${ }^{[213]}$. The molecules can counteract the proinflammatory state in asthmatic individuals' airways, modifying the disease activity.

\subsection{Mental health}

The gut-brain axis concept can be traced back to the early $20^{\text {th }}$ century, where the gut's functional integrity and microbes were attributed as part of the pathophysiology of mental health disorders ${ }^{[214]}$. Researchers back then have believed that autointoxication can affect one's mental health ${ }^{[214]}$. They suggested that toxic gut content can have a profound impact on the brain ${ }^{[214]}$. In recent years, there are increasing studies supporting this bi-directional relationship between the brain and the gut ${ }^{[215,216]}$. The gut microbes produce metabolites and molecules that can modulate the immune system, which interacts with the brain; vice versa, the brain can alter the composition of gut microbiome via neural signaling ${ }^{[217]}$.

Homeostasis of the gut microbiome has been shown to protect intestinal and blood-brain barrier integrity. Disruption of this balance allows pathogenic microbes to overgrow and induce local inflammation. They then increase the gut permeability, allowing translocation of gut content into the systemic circulation, which triggers a systemic immune response ${ }^{[218]}$. A pro-inflammatory state is shown to alter the integrity of the blood-brain barrier ${ }^{[219]}$. This allows immunomodulatory substances and pathogenic microbes to reach the brain ${ }^{[219]}$.

On the other hand, some gut microbes produce metabolites that indirectly modify the brain function via the neural signaling pathway ${ }^{[220]}$. In short, this illustrates the imbalance in the gut ecosystem can affect brain function, which predisposes individuals to the development of mental health disorders. Various studies have supported this view where a pro-inflammatory state has been observed in individuals with mental health disorders. For instances, raised inflammatory mediators, inflammatory markers, and antibodies specific to gut commensal is observed in individuals with major depressive disorders ${ }^{[221,222]}$, higher activated level of c1q in individuals with schizophrenia, and increased intestinal permeability ${ }^{[223]}$ and inflammatory state in individuals with autistic spectrum disorders ${ }^{[224]}$.

Besides that, some gut microbes are known to secrete substances that can act as neuromodulators ${ }^{[225]}$. For example, Lactobacilli spp. produces gamma-aminobutyric acid; Bacillus, Escherichia and Saccharomyces spp. produce noradrenaline; Streptococcus, Enterococcus, and Candida spp. produce serotonin (5-HT), and Bacillus produces dopamine [226]. The balance of these neuronal signaling messengers is crucial in the functioning of 
cognition and behavior of individuals. Matsumo et al. exhibited that dopamine concentrations were two fold higher in germ-free (GF) mice than in ex-germ-free mice ${ }^{[227]}$.

Meanwhile, another study showed that GF mice have a higher level of 5-HT and their metabolite in the hippocampus. This can occur without alteration in the expression of genes responsible for their production ${ }^{[228]}$. A 'healthy gut flora' is essential in the balance of neurotransmitter levels of the brain. The alteration in neurotransmitters has been attributed as the mechanism behind various mental diseases. It can be extrapolated that the homeostasis of the gut ecosystem is important in preserving healthy mental states.

\subsection{Autism spectrum disorder}

DSM-5 defines autism spectrum disorder (ASD) as a neurodevelopmental disorder characterized by impaired communication and interactions with repetitive and/or restricted behaviors ${ }^{[229]}$. The disease is considerably associated with various comorbidities, including epilepsy, bowel disorders, and sleep disorders ${ }^{[230]}$. The exact cause of autism spectrum disorder is still unknown despite strong genetic evidence ${ }^{[231,232]}$ and environmental factors. Genetic factors have been estimated to contribute to half of the ASD cases ${ }^{[231,232]}$, with the remaining contributed by ecological and other risk factors.

Considering the gut-brain axis concept, studies have explored the possible association between the gut microbiome and ASD. ASD children were found to have more bowel disorders, including abdominal pain, constipation, diarrhea, and gastric reflux ${ }^{[233,234]}$. It will be worth finding a causal relationship between gut dysbiosis, which contributes to bowel disorders, and autistic behavior in ASD individuals. Exciting to note that not until recently, the effect of microbiota transfer therapy has been shown to improve the behavioral symptoms of ASD for at least 8 weeks ${ }^{[235]}$. This further supports the direction of investigating the link between the gut microbiome and ASD as it shows the possibility of reversing autistic behavior with alteration of gut flora.

It is found that children with ASD have a deficit in gut integrity ${ }^{[236]}$ and a discrepancy in the gut microbiome's n composition instead of healthy individuals. Studies over the years have noted the differences in gut microbiota between healthy versus ASD individuals, with some common findings including Clostridium spp., Prevotella spp., Bifidobacterium spp., Candida spp., and Firmicutes spp., to be greater in population and lacking anaerobic bacteria

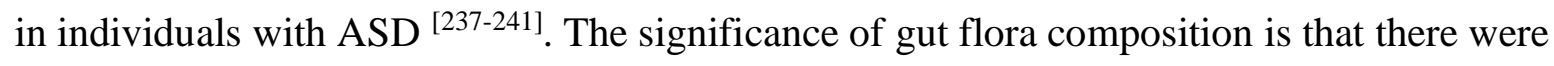
events where children treated with antibiotics developed chronic diarrhea, followed by regressive symptoms ${ }^{[237,240,242,243]}$. These clinical progressions may be due to the altered gut microbiome's antibiotics' consequences ${ }^{[244]}$.

Clostridium spp., especially C. bolteae, C. perfringens, C. difficile ${ }^{[237]}$ and $C$. histolyticum $^{[239]}$, is abundant gut flora of ASD children. It is suggested that they play a role in developing autistic behavior via neurotoxin $\rho$-cresol production ${ }^{[243,245]}$, which is evident 
by the raised serum level of p-cresol chemically similar metabolites in ASD children ${ }^{[245]}$. The toxin produced by the gut microbes can be transported by the vagus nerve directly into the brain ${ }^{[243]}$. The toxin then affects the cleaving of synaptic vesicle membrane protein, affecting the release of neurotransmitters ${ }^{[243]}$. This lowered neurotransmitter level causes behavioral changes, which are observed to be in parallel with the characteristic behavior of ASD children ${ }^{[243]}$. In addition, a higher concentration of Clostridium spp. is associated with more severe autistic symptoms ${ }^{[246]}$. The notion is further supported by the transient improvement of ASD symptoms in individuals with regressive autism treated with

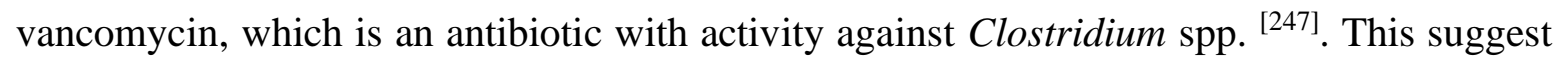
that Clostridium spp. may be a potential cause of regressive autism, but subsequent controlled studies have yet to replicate the results.

Besides that, Candida spp. has also been recently found to be associated with ASD ${ }^{[246]}$. Gut dysbiosis in individuals with ASD has allowed this commensal's overgrowth, producing propionic acids and ammonia ${ }^{[248]}$. These metabolites have been shown to react and result in beta-alanine production, chemically like inhibitory neurotransmitter gamma-aminobutyric acid (GABA) found in the brain. Assuming if the beta-alanine can cross the blood-brain barrier ${ }^{[249]}$, they can occupy the GABA receptors ${ }^{[250]}$ in human brain tissues, thus stimulating the compensatory production of GABA ${ }^{[251]}$. This excess in GABA is in keeping with the increased GABA concentration observed in children with ASD ${ }^{[251]}$. Further studies can be done to determine whether the raised level of beta-alanine observed in individuals with ASD does function similarly as suggested and subsequently triggering the remaining chain of reaction, leading to the development of ASD ${ }^{[252]}$.

Other organisms are being studied for their association with ASD, but no significant results have been found, or the mechanisms of them causing ASD is yet to be explained ${ }^{[253]}$. As discussed, gut dysbiosis is a possible mechanism that leads to the development of ASD. Factors that may alter the gut flora include antibiotics ${ }^{[253]}$, diets, variation in genetic and medical heterogeneity, and comorbidities. Pinpointing the exact cause of gut dysbiosis, which subsequently leads to ASD impossible ${ }^{[254]}$.

Finally, increased intestinal permeability in ASD children allows the escape of gut content into the systemic circulation, thus leading to a systemic pro-inflammatory state. This corresponds with the chronically raised cytokine levels observed in individuals with ASD, and some of these inflammatory mediators (IL-1 $\beta$, IL-6, IL-8, and IL-12p40) are linked explicitly to low social interaction and communication ${ }^{[255,256]}$. In short, further studies are needed to identify the exact organisms and their mechanisms in the development of ASD and recognize factors that may alter the homeostasis and integrity of the gut, leading to the development of ASD. 


\subsection{Alzheimer's disease}

Alzheimer's disease (AD) is a neurodegenerative disease characterized by progressive cognitive function loss ${ }^{[257]}$. The most widely accepted mechanism that leads to AD is the deposition of amyloid plaques and neurofibrillary tangles ${ }^{[257]}$. However, the exact cause of this deposition is still unknown and is believed, to date, to be multifactorial ${ }^{[258]}$. With the emergence of the gut-brain axis, AD has also been attributed to gut dysbiosis ${ }^{[257,259]}$.

Disease progression of $\mathrm{AD}$ has been hypothesized to be due to chronic inflammation following deposition of amyloid plaques ${ }^{[260]}$. However, recent studies have shown that these plaques possess antimicrobial activities, suggesting that neuroinflammation may cause the deposition of these plaques instead of vice versa ${ }^{[258]}$. Moreover, a study suggests that amyloid plaques and neuroinflammation deposition is a vicious cycle ${ }^{[261]}$. Thus, there is now a chronic inflammatory state in the brain tissue of individuals with AD. More studies are needed to fill the gap of causal effect relationships between amyloid plaques and neuroinflammation.

When considering the possibility of the gut microbiome affecting neuronal functions, animal studies have shown a significant reduction of amyloid plaques in germ-free mice ${ }^{[262]}$. Nonetheless, when gut microbiota is reintroduced, the mice demonstrated an increase in cerebral amyloid plaques pathology ${ }^{[262]}$. This is further supported by several studies that showed that gut infection is associated with $\mathrm{AD}$ development ${ }^{[258]}$. For example, individuals infected by Borrelia burgdorferi and $H$. pylori have been observed to have raised serum A $\beta 40$ and $\mathrm{A} \beta 42$, which is a biomarker of $\mathrm{AD}{ }^{[263]}$. These pathogens may also contribute to AD's development by inducing an inflammatory response in the brain ${ }^{[264]}$. AD individuals have an abundance of pro-inflammatory microbiome and reduced anti-inflammatory gut microbes ${ }^{[265]}$. Some of these pathogenic microbes can secrete pro-inflammatory neurotoxins, which can affect the neurofunction ${ }^{[266]}$. Another pathology observed in AD is the reduction of BDNF proteins in the hippocampus ${ }^{[258]}$. It is showed that probiotics have been able to reverse this in the mice model, suggesting that specific gut microbiome are protective and needed for the brain's normal functioning ${ }^{[267]}$.

Recent breakthroughs in discovering the superior temporal lobe and hippocampus lysates of individuals with $\mathrm{AD}$ are saturated with lipopolysaccharide ${ }^{[266]}$. This could be due to the gram-negative gut microbes, which can stimulate local inflammation, disrupting the gut barrier, allowing the translocation of gut microbes, and endotoxins into the systemic circulation ${ }^{[268]}$. When these molecules such as lipopolysaccharides reach the brain, it can induce local inflammation or affect the nerve functions directly or indirectly ${ }^{[269]}$. On the other hand, some gut microbes can produce neuroprotective molecules such as short-chain fatty acids, and losing these protective microbes can alter brain tissue's normal function ${ }^{[258]}$. For instance, Li et al. have shown that Clostridium butyricum species can enhance the intestinal and blood brain barrier structural integrity and improve neurodegeneration symptoms ${ }^{[270] .}$ 
Is it also known that our gut microbiome changes physiologically as we age ${ }^{[258]}$. There is an increase in Proteobacteria and reduction of probiotics (Bifidobacteria) and SCFA producing microbes ${ }^{[271]}$. The significant decrease in functioning microbiome, especially those with SCFA is their deficit associated with raised inflammatory mediators ${ }^{[272]}$. This aging-related pro-inflammatory state is known as inflamm-aging. It is the common pathology for a wide range of age-related diseases, including degeneration of cognitive functions in $\mathrm{AD}^{[273]}$ and increased $\mathrm{AD}$ prevalence with age.

\section{Emerging treatments}

\section{Probiotics}

Probiotics are live microorganisms that have numerous benefits for our health when consumed ${ }^{[274]}$. The story of probiotics begins about a century ago, where the process of fermentation was initially used as a means of food preservation ${ }^{[275]}$. With people starting to notice the health benefits of consuming fermented food, this food was adapted for various uses. For example, treatment of diseases and consumption for energy and strength ${ }^{[275]}$. Elie Metchnikoff, an immunologist, suggested that probiotics found in fermented food can improve health and increase lives ${ }^{[274]}$. This, later, created a ripple effect, encouraging more scientists to venture into the discovery of probiotics. They believe that not all bacteria are pathogenic, and some of them can replace the pathogenic flora, creating a healthy gut microbiome.

With the blooming studies on the gut health axis, therapies to create a 'healthy' gut flora are always searching. With the known effect of probiotics, it is not surprising that probiotics are proposed as one of the therapeutic options. Probiotics are suggested to confer its effect by preventing pathogenic microbes' overgrowth, enhancing the gut's structural and functional integrity, and modulating the gut immune system ${ }^{[18]}$. This effect is conferred by the probiotics' cell-surface architecture, such as their surface proteins and capsule. This can be done by various mechanisms that include enhancing natural killer cells, immune phagocytes, or upregulation of antibodies ${ }^{[276,277]}$. To date, there are numerous studies on various health diseases and probiotics use, with some showing promising results. For instance, probiotics use has been shown to reduce the duration of diarrhea in acute gastroenteritis and $C$. difficile infection ${ }^{[278,279]}$, inducing more prolonged remission in IBD ${ }^{[280,281]}$ and modulating the immune response in patients with allergy ${ }^{[282,283]}$. Some probiotics strains can increase antiinflammatory mediators' concentration, such as tumor necrosis factors, which can abate diseases ${ }^{[276,284]}$.

Traditionally, the most widely used yeast strain is the Saccharomyces cerevisiae, whereas the most common bacterial probiotics are the Bifidobacterium and Lactobacillus species ${ }^{[285]}$. For instance, L. plantarum, L. rhamnosus, B. bifidum, and B. breve ${ }^{[286]}$. There is a variation of the functions between different probiotics strains, even if there are of the same species ${ }^{[285]}$. For example, strains that initially fail to prevent necrotizing enterocolitis 
in infants ${ }^{[287]}$, will successfully prevent sepsis when replaced with another formulation ${ }^{[288]}$. Thus, it will be imperative to evaluate the functions and efficacy of each of these strains of probiotics for disease treatment ${ }^{[285]}$. Another issue with probiotics is worth noting because its overall effectiveness is also influenced by the host factors, including the baseline gut microbiome ${ }^{[28]}$. Maldonado et al. have shown that the efficacy of probiotic Bifidobacterium longum subsp. Longum AH1206 is the highest if the host has low abundance of B. longum and carbohydrate metabolizing genes ${ }^{[289]}$

However, disappointing results contradict the positive outcomes with probiotics use ${ }^{\text {[290- }}$ 292]. Also, there were reported events of adverse effects associated with probiotics consumption ${ }^{[293]}$. The significant side effects are particularly concerned in individuals with an immunodeficiency. They are at risk of sepsis, bacteremia, or endocarditis with probiotics consumption ${ }^{[285]}$. This makes the current recommendation of probiotics as a therapeutic option impossible. The studies cannot conclude as there is always discrepancy on the type of probiotics, criteria of the selected population, and the outcomes ${ }^{[293]}$. Thus, we cannot know which particular strains are beneficial and which populations will benefit the most from probiotics consumption ${ }^{[293]}$. Besides that, there are also insufficient studies to identify people at risk of consuming probiotics ${ }^{[293]}$. This issue needs to be addressed in view that probiotics may be a potential therapeutic option in the future. Furthermore, there is still difficulty explaining probiotics' outcomes on human health via mechanisms found in laboratory studies ${ }^{[290]}$. This makes it difficult to extrapolate the effect of probiotics on human diseases ${ }^{\text {[290] }}$.

It is known that alteration of gut microbes can affect the gut's functional and structural integrity, which can affect other host's organ systems. With this strong relationship between gut dysbiosis and various health diseases, it is still worth continuing the search for the effect of probiotics on human health. The probiotic use has been recommended in some clinical guidelines for children in antibiotic-associated diarrhea, acute infectious diarrhea, necrotizing enterocolitis, infantile colic, ulcerative colitis, and irritable bowel disease ${ }^{[294,295]}$. However, there is still no clinical recommendations for the clinical use of probiotics in adults [28]. Current research has been exploring different human commensals other than the traditional genera Bifidobacterium and Lactobacillus in view that different strains have distinctive effects on the host ${ }^{[28]}$. This research also needs to be gradually moved on to human trials after confirming its safety profile and efficacy on animal experiments ${ }^{[296]}$. It is also essential to understand that the outcomes depend on the formulations, participants, doses, and clinical endpoint ${ }^{[28]}$. Perhaps, with more standardized trials done, we will be able to come out with a more definite conclusion on the clinical use of probiotics ${ }^{[290]}$.

Prebiotics and dietary fibers

Fiber is plant-derived food that cannot be digested by the human gastrointestinal tract

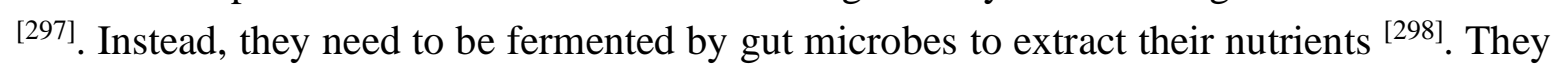
are various kind of fibers which can be derived from different plants ${ }^{[299,300]}$. Each of them 
possesses specific properties and has other effects on the host when consumed ${ }^{[300]}$. If the fibers can modify the gut microbiome in such a way that confers health benefits, they can be considered prebiotics ${ }^{[301]}$. This modification includes altering the microbiome's composition, regulating the activities and metabolites produced by the microbes beneficial to the host ${ }^{[302]}$.

A diet low in fibers has been shown to shift the gut microbiome drastically. Human trials have demonstrated that a switch from a high fiber plant-based diet to a fiber-deprived meatbased diet can cause significant changes within as short as 24 hours ${ }^{[303]}$. Also, fibers deprived of fiber is associated with reduced biodiversity of the gut microbiome ${ }^{[304]}$. This is supported by the depleted diversity of gut microbiota observed in mice fed with fiber depleted diet ${ }^{[305]}$. However, this deprivation is reversible by re-introducing a high fiber diet ${ }^{[306]}$. This reversibility of gut flora biodiversity may shine a light on various diseases that have been associated with the low diversity of gut microbes. This suggests that a diet high in fibers can help maintain the gut microbiome's homeostasis, preventing pathogenic microbes from causing various physical and mental diseases.

The fermentation end products are mainly short-chain fatty acids (SCFA), which confers invaluable benefits to human health ${ }^{[303]}$. For instance, Lactobacilli spp. produces metabolites, including SCFA, via fermentation of fibers with anti-carcinogenic effect ${ }^{[307]}$. They have been shown to prevent colorectal cancer by reducing the $\mathrm{pH}$ of colorectal cancer ${ }^{\text {[307] }}$. On the other hand, lacking of SCFA has been observed in individuals with IBD due to their depletion of SCFA producing bacteria ${ }^{[308]}$. Depriving SCFA means the host has lost its ability to inhibit pro-inflammatory state activation, as in individuals with IBD. This is supported by the reduction of inflammatory markers via the consumption of prebiotics ${ }^{[309]}$. Moreover, specific prebiotics such as psyllium, beta-glucans, and pectins are classified as high glycemic index food ${ }^{[299]}$. They possess unique properties of slowing glucose absorption, which can benefit patients with metabolic disorders ${ }^{[299,310]}$.

Interestingly, despite the unknown mechanism, prebiotics has been shown to suppress type $2 \mathrm{~T}$ helper responses, which can have an immunomodulatory effect on individuals with atopy diseases [311,312]. Arslanoglu et al. have shown that infants fed with prebioticsupplemented hypoallergenic formula had a lower risk of allergies in pre-school age ${ }^{[313]}$. Moreover, animal studies have shown that prebiotics that can promote the growth of protective gut microbes, in which intestinal permeability is reduced, the concentration of endotoxin is decreased, thus reducing the prevalence of metabolic disorders ${ }^{[314]}$

When extrapolating prebiotic use into clinical use, the evidence is still insufficient compared to probiotics ${ }^{[28]}$. There are currently no clinical guidelines recommending prebiotic use in neither the pediatric nor adult population ${ }^{[28]}$. As with probiotics, studies have shown that prebiotics' effectiveness depends on the baseline gut flora, which can be influenced by multiple factors such as age, diet, and lifestyle [315, 316]. Besides that, formulations, participants, doses, and clinical endpoints must be considered when planning 
future research. All these factors can influence prebiotic use's effectiveness compared with probiotics ${ }^{[28]}$.

When discussing therapies' safety profile, prebiotics seems to have minimal lifethreatening side effects compared to probiotics ${ }^{[317]}$. They are mostly harmless and just indigestible fibers. Thus, the most probable side effects are the osmotic functions of the prebiotics' fermented product ${ }^{[317]}$. For example, prebiotic consumption can cause osmotic diarrhea, flatulence, and abdominal cramps ${ }^{[317]}$. Interestingly, the safety profile is dosedependent, and the therapeutic dose is usually low. This implicates that if consumed appropriately, the side effects of prebiotics are usually mild ${ }^{[318]}$. A further advantage of prebiotics is that it's convenient in production, storage, and transportation compared to probiotics and fecal transplantation ${ }^{[317]}$. It does not need to be preserved via a cold chain makes the whole process of making prebiotics available to the patients much easier ${ }^{[317]}$. Overall, a diet high in fibers and prebiotics has multiple benefits for our health and can play a disease-modifying role in various diseases. With more human trials done, perhaps it can be a potential intervention and recommended therapeutic option for many conditions.

\section{Fecal microbiota transplantation}

Fecal microbiota transplantation (FMT) transfers gut microbes from a donor to a recipient, either by infusion into the colon by colonoscopy or delivered via upper gastrointestinal tract such as capsule ingestion, by gastroenteric tube or endoscope ${ }^{\text {[303] }}$. This procedure was reported as early as 1958 by Eiseman et al., where few patients with pseudomembranous colitis recovered after receiving FMT ${ }^{[319]}$. Fischer et al., also showed the beneficial effect of FMT on individuals with severe and severe-complicated Clostridium difficile infection ${ }^{[320]}$. They have shown promising results with a significant cure rate in all the participants ${ }^{[320]}$. The increasing studies on the association between gut microbes and health diseases have created ripples to modify the gut microbiota as a therapeutic option for gut dysbiosis related health diseases ${ }^{[268,321]}$. With the success of FMT in the treatment of Clostridium difficile infection, FMT seems to be a plausible method to help modify other diseases related to disruption of the gut microbiome.

Currently, FMT has been adopted by the U.S guidelines second-line treatment for recurrent Clostridium difficile infection ${ }^{[322]}$. At the same time, the European proposed FMT guidelines after the first episode of severe and refractory $C$. difficile infection ${ }^{[323]}$. It is also showing promising experimental results in gut dysbiosis related diseases such as IBD [324, ${ }^{325]}$, metabolic syndrome ${ }^{[326]}$, and autism spectrum disorder ${ }^{[235]}$ but all of them are still in the experimental phase ${ }^{[23]}$. The donor stools for FMT can be obtained from either universal donors via stool banks or patient-directed donors ${ }^{[327]}$. Patient-directed donors have been less frequent as it is more time-consuming to collect, screen, and process, leading to treatment delay ${ }^{[328]}$. Also, the donor chosen may feel vulnerable for their confidential information ${ }^{[329]}$. Thus, the most preferred option to date is the universal donor FMT. Stools are collected from 
young adults who have passed the screening test ${ }^{[330]}$. The advantage of universal donors is that recipients can receive microbiome from multiple donors who may provide a greater diversity of microbes instead of receiving only the gut flora from a single donor. This is further supported by an RCT which showed that multidoor recipients showed improvement in the disease progression of ulcerative colitis ${ }^{[331]}$.

With the increase in popularity and evidence on the efficacy of FMT, stool banks such as OpenBiome have emerged ${ }^{[332]}$. They are usually strict criteria to screen donors, standardized protocols for stool handling, processing, and delivering. However, there is a concern that some infections may go undetectable, which may risk infecting the recipients ${ }^{[332]}$. To note that a few years back, the FDA has been alerting health practitioners and patients on the potentially severe and life-threatening infections due to FMT. However, in these cases, pathogens have been identified from the fecal transplantation product ${ }^{[333]}$. Thus, a regulated protocol on FMT should be detailed enough to maximize reproducible outcomes and minimize adverse events to patients ${ }^{[34]}$. Other than the risk of infection, typical side effects with FMT are loose stools and bloating, which usually resolve spontaneously within a day ${ }^{[335]}$. Also, the long-term impact and risks of FMT are still unknown. Longer-term follow-ups must fill this gap. Lastly, it is still unknown what constitutes a 'healthy' gut microbiome, which can be the 'ideal' fecal microbiota for transplantation. We are assuming healthy individuals have 'healthy' microbiota. More research on the genomes of microbes required for good health is crucial for understanding the mechanism behind FMT ${ }^{[336]}$.

\section{Conclusion}

From this review, we know a strong association between the gut microbiome and various diseases, regardless of whether it is a physical or mental disorder. The structural and functional integrity of the gastrointestinal tract is imperative in the maintenance of good health. Disruption of gut homeostasis has been demonstrated to contribute to the development of diseases. Meanwhile, the microbes can be categorized into protective and pathogenic subgroups. Different species have their mechanism in disrupting or protecting the gut flora. If the gut's homeostasis is lost, local inflammation will lead to gut microbes' translocation, leading to a pro-inflammatory state observed in various diseases. Some toxins or beneficial SCFA molecules can also influence other systems such as metabolic and neurofunction by several pathways.

Moreover, we have now known that we may reverse or alter gut-dysbiosis-related diseases by modifying the gut microbiome ${ }^{[337]}$. We have reviewed that probiotics, prebiotics, and fecal transplantation are potential or current therapeutic options for gut-dysbiosis associated diseases. Despite supporting data, more standardized studies are still needed to obtain a definitive outcome for their safety and beneficial use in humans. If it is proven to be effective, studies can even move on to investigate their use in disease prevention, especially with prebiotics that has minimal side effects in human studies. In conclusion, there is a strong 
association between the human microbiome and diseases. This is a potential field further to investigate the characteristic microbiome for every gut-dysbiosis related disease. With that, it may be possible to modify illnesses that have never been possible before, such as autistic spectrum disorder, which will be life changing.

Author Contributions: AW-YL performed the literature search, critical data analysis as well as manuscript writing. LT-HT, N-SAM, SHW, L-HL and VL provided review, editing, and proofreading for this manuscript. $\mathrm{L}-\mathrm{HL}$ and VL conceptualize this review writing project.

Funding: The SEED Funding funded this work from Microbiome and Bioresource Research Strength (MBRS), Jeffrey Cheah School of Medicine and Health Sciences, (Vote Number: MBRS/JCSMHS/02/2020) awarded to VL.

Acknowledgments: Professor Dr. Shajahan Yasin, Professor, and Head of School, Jeffrey Cheah School of Medicine and Health Sciences, Monash University Malaysia.

Conflicts of Interest: The authors declare no conflict of interest.

\section{References}

1. Ser H-L, Tan LT-H, Law JW-F, et al., Genomic analysis of severe acute respiratory syndrome coronavirus 2 (SARS-CoV-2) strains isolated in Malaysia. Prog Microbes Mol Biol 2020; 3(1).

2. Johnson D, Ren SEC, Johnson HD, et al., COVID-19: Are Malaysians embracing or suffering the new normality? Prog Microbes Mol Biol 2020; 3(1).

3. Letchumanan V, Ab Mutalib N-S, Goh B-H, et al., Novel coronavirus 2019-nCoV: Could this virus become a possible global pandemic. Prog Microbes Mol Biol 2020; 3(1).

4. Ceylan Z, Estimation of COVID-19 prevalence in Italy, Spain, and France. Sci Total Environ 2020; $729: 138817$.

5. Ser H-L, Letchumanan V, Law JW-F, et al., PMMB COVID-19 Bulletin: Spain (18th April 2020). Prog Microbes Mol Biol 2020; 3(1).

6. Tan LT-H, Letchumanan V, Ser H-L, et al., PMMB COVID-19 Bulletin: United Kingdom (22nd April 2020). Prog Microbes Mol Biol 2020; 3(1).

7. Lee VS, Chong WL, Sukumaran SD, et al., Computational screening and identifying binding interaction of antiviral and anti-malarial drugs: Toward the potential cure for SARS-CoV-2. Prog Drug Discov Biomed Sci 2020; $3(1)$.

8. Aagaard K, Luna RA, and Versalovic J, The human microbiome of local body sites and their unique biology, in Mandell, Douglas, and Bennett's Principles and Practice of Infectious Diseases. 8th ed. Philadelphia, PA: Elsevier Saunders. 2015. p. 11-8.

9. Eckburg PB, Bik EM, Bernstein CN, et al., Diversity of the human intestinal microbial flora. Science 2005; 308(5728): 1635-1638.

10. Sender R, Fuchs S, and Milo R, Are we really vastly outnumbered? Revisiting the ratio of bacterial to host cells in humans. Cell 2016; 164(3): 337-340.

11. Costello EK, Lauber CL, Hamady M, et al., Bacterial community variation in human body habitats across space and time. Science 2009; 326(5960): 1694-1697.

12. Caporaso JG, Lauber CL, Costello EK, et al., Moving pictures of the human microbiome. Genome Biol 2011; 12(5): R50.

13. Donaldson GP, Lee SM, and Mazmanian SK, Gut biogeography of the bacterial microbiota. Nat Rev Microbiol 2016; 14(1): 20-32. 
14. Oh J, Byrd AL, Deming C, et al., Biogeography and individuality shape function in the human skin metagenome. Nature 2014; 514(7520): 59-64.

15. Cani PD, Everard A, and Duparc T, Gut microbiota, enteroendocrine functions and metabolism. Curr Opin Pharmacol 2013; 13(6): 935-940.

16. Flint HJ, Scott KP, Louis P, et al., The role of the gut microbiota in nutrition and health. Nat Rev Gastroenterol Hepatol 2012; 9(10): 577.

17. Cebra JJ, Influences of microbiota on intestinal immune system development. Am J Clin Nutr 1999; 69(5): 1046s$1051 \mathrm{~s}$.

18. Round JL and Mazmanian SK, The gut microbiota shapes intestinal immune responses during health and disease. Nat Rev Immunol 2009; 9(5): 313-323.

19. Thaiss CA, Zmora N, Levy M, et al., The microbiome and innate immunity. Nature 2016; 535(7610): 65-74.

20. Durack J and Lynch SV, The gut microbiome: Relationships with disease and opportunities for therapy. J Exp Med 2019; 216(1): 20-40.

21. Kho ZY and Lal SK, The human gut microbiome-a potential controller of wellness and disease. Front Microbiol 2018; 9: 1835 .

22. Johnson D, Letchumanan V, Thurairajasingam S, et al., A Revolutionizing Approach to Autism Spectrum Disorder Using the Microbiome. Nutrients 2020; 12(7): 1983.

23. Lee L-H, Letchumanan V, Khan TM, et al., Dissecting the gut and skin: budding association between gut microbiome in the development to psoriasis? Gut 2019: A41.

24. Lee L-H, Letchumanan V, Khan TM, et al., Role of human microbiota in skin dermatitis and eczema: a systematic review. Gut 2018: A19.

25. Lee L-H, Ser H-L, Khan TM, et al., Relationship between autism and gut microbiome: current status and update. Gut 2019: A40-41.

26. Durganaudu H, Kunasegaran T, and Ramadas A, Dietary Glycaemic Index and Type 2 Diabetes Mellitus: Potential Modulation of Gut Microbiota. Prog Microbes Mol Biol 2020; 3(1).

27. Selvaraj SM, Wong SH, Ser H-L, et al., Role of Low FODMAP Diet and Probiotics on Gut Microbiome in Irritable Bowel Syndrome (IBS). Prog Microbes Mol Biol 2020; 3(1).

28. Sanders ME, Merenstein DJ, Reid G, et al., Probiotics and prebiotics in intestinal health and disease: from biology to the clinic. Nat Rev Gastroenterol Hepatol 2019: 1-12.

29. Quigley EM, Prebiotics and probiotics in digestive health. Clin Gastroenterol Hepatol 2019; 17(2): 333-344.

30. Funkhouser LJ and Bordenstein SR, Mom knows best: the universality of maternal microbial transmission. PLoS Biol 2013; 11(8).

31. Walker RW, Clemente JC, Peter I, et al., The prenatal gut microbiome: are we colonized with bacteria in utero? Pediatr Obes 2017; 12: 3-17.

32. Lee JK-F, Hern Tan LT, Ramadas A, et al., Exploring the Role of Gut Bacteria in Health and Disease in Preterm Neonates. Int J Environ Res Public Health 2020; 17(19): 6963.

33. Madan JC, Hoen AG, Lundgren SN, et al., Association of cesarean delivery and formula supplementation with the intestinal microbiome of 6-week-old infants. JAMA Pediatr 2016; 170(3): 212-219.

34. Benner M, Ferwerda G, Joosten I, et al., How uterine microbiota might be responsible for a receptive, fertile endometrium. Hum Reprod Update 2018; 24(4): 393-415.

35. Ardissone AN, Diomel M, Davis-Richardson AG, et al., Meconium microbiome analysis identifies bacteria correlated with premature birth. PLoS One 2014; 9(3): e90784. 
36. Faa G, Gerosa C, Fanni D, et al., Factors influencing the development of a personal tailored microbiota in the neonate, with particular emphasis on antibiotic therapy. J Matern Fetal Neonatal Med 2013; 26(sup2): 35-43.

37. Chu DM, Ma J, Prince AL, et al., Maturation of the infant microbiome community structure and function across multiple body sites and in relation to mode of delivery. Nat Med 2017; 23(3): 314.

38. Chu DM, Meyer KM, Prince AL, et al., Impact of maternal nutrition in pregnancy and lactation on offspring gut microbial composition and function. Gut Microbes 2016; 7(6): 459-470.

39. Aagaard K, Stewart CJ, and Chu D, Una destinatio, viae diversae. EMBO reports 2016; 17(12): 1679-1684.

40. Ho NT, Li F, Lee-Sarwar KA, et al., Meta-analysis of effects of exclusive breastfeeding on infant gut microbiota across populations. Nat Commun 2018; 9(1): 1-13.

41. Dominguez-Bello MG, Costello EK, Contreras M, et al., Delivery mode shapes the acquisition and structure of the initial microbiota across multiple body habitats in newborns. Proc Natl Acad Sci 2010; 107(26): 11971-11975.

42. Koenig JE, Spor A, Scalfone N, et al., Succession of microbial consortia in the developing infant gut microbiome. Proc Natl Acad Sci 2011; 108(Supplement 1): 4578-4585.

43. Walker AW, Ince J, Duncan SH, et al., Dominant and diet-responsive groups of bacteria within the human colonic microbiota. ISME J 2011; 5(2): 220-230.

44. Wu GD, Chen J, Hoffmann C, et al., Linking long-term dietary patterns with gut microbial enterotypes. Science 2011; 334(6052): 105-108.

45. Earle KA, Billings G, Sigal M, et al., Quantitative imaging of gut microbiota spatial organization. Cell Host Microbe 2015; 18(4): 478-488.

46. Li H, Qi Y, and Jasper H, Preventing age-related decline of gut compartmentalization limits microbiota dysbiosis and extends lifespan. Cell Host Microbe 2016; 19(2): 240-253.

47. Dethlefsen L and Relman DA, Incomplete recovery and individualized responses of the human distal gut microbiota to repeated antibiotic perturbation. Proc Natl Acad Sci 2011; 108(Supplement 1): 4554-4561.

48. Byrne JP, Encyclopedia of the black death. Vol. 1. 2012: ABC-CLIO.

49. Young VB, The role of the microbiome in human health and disease: an introduction for clinicians. BMJ 2017; 356: j831.

50. Gibbons SM and Gilbert JA, Microbial diversity-exploration of natural ecosystems and microbiomes. Curr Opin Genet Dev 2015; 35: 66-72.

51. Wang B, Yao M, Lv L, et al., The human microbiota in health and disease. Engineering 2017; 3(1): 71-82.

52. Lee L-H, Letchumanan V, Tan LT-H, et al., Gut-skin axis: decoding the link between the gut microbiome and hives. Gut 2020; 69(Suppl 2): A17-A18.

53. Lee L-H, Law JW-F, Tan LT-H, et al., Budding association between gut microbiome in the development of Myasthenia Gravis. Gut 2020; 69(Suppl 2): A17-A18.

54. Lee L-H, Tan LT-H, Letchumanan V, et al., A moulding game: the role of gut microbiome in osteoporosis. Gut 2020; 69(Suppl 2): A18-A19.

55. Mottawea W, Chiang C-K, Mühlbauer M, et al., Altered intestinal microbiota-host mitochondria crosstalk in new onset Crohn's disease. Nat Commun 2016; 7(1): 1-14.

56. Sartor RB, Microbial influences in inflammatory bowel diseases. Gastroenterology 2008; 134(2): 577-594.

57. Kostic AD, Xavier RJ, and Gevers D, The microbiome in inflammatory bowel disease: current status and the future ahead. Gastroenterology 2014; 146(6): 1489-1499. 
58. Evans WE, Horner M, Chu YQ, et al., Altered mercaptopurine metabolism, toxic effects, and dosage requirement in a thiopurine methyltransferase-deficient child with acute lymphocytic leukemia. J Pediatr 1991; 119(6): 985989.

59. Fujimura KE, Sitarik AR, Havstad S, et al., Neonatal gut microbiota associates with childhood multisensitized atopy and T cell differentiation. Nat Med 2016; 22(10): 1187

60. Morgan XC, Tickle TL, Sokol H, et al., Dysfunction of the intestinal microbiome in inflammatory bowel disease and treatment. Genome Biol 2012; 13(9): R79.

61. Shah R, Cope JL, Nagy-Szakal D, et al., Composition and function of the pediatric colonic mucosal microbiome in untreated patients with ulcerative colitis. Gut microbes 2016; 7(5): 384-396.

62. Gilbert JA, Quinn RA, Debelius J, et al., Microbiome-wide association studies link dynamic microbial consortia to disease. Nature 2016; 535(7610): 94-103.

63. Takaishi H, Matsuki T, Nakazawa A, et al., Imbalance in intestinal microflora constitution could be involved in the pathogenesis of inflammatory bowel disease. Int J Med Microbiol 2008; 298(5-6): 463-472.

64. Mazamaniam S, Round J, and Kasper D, A microbial symbiosis factor prevents inflammatory disease. Nature 2008; 453: 620-5

65. Cohen LJ, Cho JH, Gevers D, et al., Genetic factors and the intestinal microbiome guide development of microbebased therapies for inflammatory bowel diseases. Gastroenterology 2019.

66. Jostins L, Ripke S, Weersma RK, et al., Host-microbe interactions have shaped the genetic architecture of inflammatory bowel disease. Nature 2012; 491(7422): 119-124.

67. Liu JZ, Van Sommeren S, Huang H, et al., Association analyses identify 38 susceptibility loci for inflammatory bowel disease and highlight shared genetic risk across populations. Nat Genet 2015; 47(9): 979.

68. Petnicki-Ocwieja T, Hrncir T, Liu Y-J, et al., Nod2 is required for the regulation of commensal microbiota in the intestine. Proc Natl Acad Sci 2009; 106(37): 15813-15818.

69. Hisamatsu T, Suzuki M, Reinecker H-C, et al., CARD15/NOD2 functions as an antibacterial factor in human intestinal epithelial cells. Gastroenterology 2003; 124(4): 993-1000.

70. Lavoie S, Conway KL, Lassen KG, et al., The Crohn's disease polymorphism, ATG16L1 T300A, alters the gut microbiota and enhances the local Th1/Th17 response. Elife 2019; 8: e39982.

71. Li E, Hamm CM, Gulati AS, et al., Inflammatory bowel diseases phenotype, C. difficile and NOD2 genotype are associated with shifts in human ileum associated microbial composition. PLoS One 2012; 7(6).

72. Conte MP, Schippa S, Zamboni I, et al., Gut-associated bacterial microbiota in paediatric patients with inflammatory bowel disease. Gut 2006; 55(12): 1760-1767.

73. Elinav E, Strowig T, Kau AL, et al., NLRP6 inflammasome regulates colonic microbial ecology and risk for colitis. Cell 2011; 145(5): 745-757.

74. Gionchetti P, Rizzello F, Venturi A, et al., Oral bacteriotherapy as maintenance treatment in patients with chronic pouchitis: a double-blind, placebo-controlled trial. Gastroenterology 2000; 119(2): 305-309.

75. Manichanh C, Rigottier-Gois L, Bonnaud E, et al., Reduced diversity of faecal microbiota in Crohn's disease revealed by a metagenomic approach. Gut 2006; 55(2): 205-211.

76. Ott S, Musfeldt M, Wenderoth $\mathrm{D}$, et al., Reduction in diversity of the colonic mucosa associated bacterial microflora in patients with active inflammatory bowel disease. Gut 2004; 53(5): 685-693.

77. Swidsinski A, Loening-Baucke V, Vaneechoutte M, et al., Active Crohn's disease and ulcerative colitis can be specifically diagnosed and monitored based on the biostructure of the fecal flora. Inflamm Bowel Dis 2008; 14(2): $147-161$. 
78. Lopez-Siles M, Duncan SH, Garcia-Gil LJ, et al., Faecalibacterium prausnitzii: from microbiology to diagnostics and prognostics. ISME journal 2017; 11(4): 841-852.

79. Lopez-Siles M, Martinez-Medina M, Abellà C, et al., Mucosa-associated Faecalibacterium prausnitzii phylotype richness is reduced in patients with inflammatory bowel disease. Appl Environ Microbiol 2015; 81(21): 75827592.

80. Tieng FYF, Abu N, Sukor S, et al., L1CAM, CA9, KLK6, HPN, and ALDH1A1 as Potential Serum Markers in Primary and Metastatic Colorectal Cancer Screening. Diagnostics 2020; 10(7): 444.

81. Lee L-H, Law JW-F, Khan TM, et al., Unveiling the anti-colon cancer potential of sarawak mangrove-derived novel streptomycetes. Gut 2019.

82. Lee L-H, Ser H-L, Ab Mutalib N-S, et al., Winning the war against colon cancer: chemo-preventive potential of novel streptomyces species derived from mangrove forest in malaysia. Gut 2018.

83. Law JW-F, Law LN-S, Letchumanan V, et al., Anticancer Drug Discovery from Microbial Sources: The Unique Mangrove Streptomycetes. Molecules 2020; 25(22): 5365.

84. Law JW-F, Letchumanan V, Tan LT-H, et al., The rising of "modern actinobacteria" era. Prog Microbes Mol Biol 2020;3(1).

85. Tan LT-H, Ser H-L, Yin W-F, et al., Investigation of antioxidative and anticancer potentials of Streptomyces sp. MUM256 isolated from Malaysia mangrove soil. Front Microbiol 2015; 6: 1316.

86. Sears CL and Garrett WS, Microbes, microbiota, and colon cancer. Cell Host Microbe 2014; 15(3): 317-328.

87. Zintzaras E, Is there evidence to claim or deny association between variants of the multidrug resistance gene (MDR1 or ABCB1) and inflammatory bowel disease? Inflamm Bowel Dis 2012; 18(3): 562-572.

88. Wu S, Rhee K-J, Albesiano E, et al., A human colonic commensal promotes colon tumorigenesis via activation of T helper type 17 T cell responses. Nat Med 2009; 15(9): 1016.

89. Gur C, Ibrahim Y, Isaacson B, et al., Binding of the Fap2 protein of Fusobacterium nucleatum to human inhibitory receptor TIGIT protects tumors from immune cell attack. Immunity 2015; 42(2): 344-355.

90. Bullman S, Pedamallu CS, Sicinska E, et al., Analysis of Fusobacterium persistence and antibiotic response in colorectal cancer. Science 2017; 358(6369): 1443-1448.

91. Mima K, Sukawa Y, Nishihara R, et al., Fusobacterium nucleatum and T cells in colorectal carcinoma. JAMA Oncol 2015; 1(5): 653-661.

92. Kostic AD, Chun E, Robertson L, et al., Fusobacterium nucleatum potentiates intestinal tumorigenesis and modulates the tumor-immune microenvironment. Cell Host Microbe 2013; 14(2): 207-215.

93. Rubinstein MR, Wang X, Liu W, et al., Fusobacterium nucleatum promotes colorectal carcinogenesis by modulating E-cadherin/ $\beta$-catenin signaling via its FadA adhesin. Cell Host Microbe 2013; 14(2): 195-206.

94. Wong RS, Apoptosis in cancer: from pathogenesis to treatment. J Exp Clin Cancer Res 2011; 30(1): 87.

95. Sobhani I, Tap J, Roudot-Thoraval F, et al., Microbial dysbiosis in colorectal cancer (CRC) patients. PLoS One 2011; 6(1).

96. Boleij A, Hechenbleikner EM, Goodwin AC, et al., The Bacteroides fragilis toxin gene is prevalent in the colon mucosa of colorectal cancer patients. Clin Infect Dis 2015; 60(2): 208-215.

97. Hermsen JL, Schurr MJ, Kudsk KA, et al., Phenotyping Clostridium septicum infection: a surgeon's infectious disease. J Surg Res 2008; 148(1): 67-76.

98. Wang T, Cai G, Qiu Y, et al., Structural Segregation of Gut Microbiota between Colorectal Cancer Patients and Healthy Volunteers. The ISME Journal, 6, 320-329. 2011. 
99. Swidsinski A, Khilkin M, Kerjaschki D, et al., Association between intraepithelial Escherichia coli and colorectal cancer. Gastroenterology 1998; 115(2): 281-286.

100. Geller LT, Barzily-Rokni M, Danino T, et al., Potential role of intratumor bacteria in mediating tumor resistance to the chemotherapeutic drug gemcitabine. Science 2017; 357(6356): 1156-1160.

101. Gao R, Gao Z, Huang L, et al., Gut microbiota and colorectal cancer. Eur J Clin Microbiol Infect Dis 2017; 36(5): 757-769.

102. Arpaia N, Campbell C, Fan X, et al., Metabolites produced by commensal bacteria promote peripheral regulatory T-cell generation. Nature 2013; 504(7480): 451-455.

103. Arthur JC, Perez-Chanona E, Mühlbauer M, et al., Intestinal inflammation targets cancer-inducing activity of the microbiota. Science 2012; 338(6103): 120-123.

104. Smith PM, Howitt MR, Panikov N, et al., The microbial metabolites, short-chain fatty acids, regulate colonic Treg cell homeostasis. Science 2013; 341(6145): 569-573.

105. Montalban-Arques A and Scharl M, Intestinal microbiota and colorectal carcinoma: Implications for pathogenesis, diagnosis, and therapy. EBioMedicine 2019.

106. Li S, Konstantinov SR, Smits R, et al., Bacterial biofilms in colorectal cancer initiation and progression. Trends Mol Med 2017; 23(1): 18-30.

107. Tomkovich S, Dejea CM, Winglee K, et al., Human colon mucosal biofilms from healthy or colon cancer hosts are carcinogenic. J Clin Invest 2019; 129(4).

108. Chew S-S, Tan LT-H, Law JW-F, et al., Targeting Gut Microbial Biofilms-A Key to Hinder Colon Carcinogenesis? Cancers (Basel) 2020; 12(8): 2272.

109. Thomas AM, Manghi P, Asnicar F, et al., Metagenomic analysis of colorectal cancer datasets identifies crosscohort microbial diagnostic signatures and a link with choline degradation. Nat Med 2019; 25(4): 667-678.

110. Wirbel J, Pyl PT, Kartal E, et al., Meta-analysis of fecal metagenomes reveals global microbial signatures that are specific for colorectal cancer. Nat Med 2019; 25(4): 679-689.

111. Oppler B, Zur Kenntniss des Mageninhalts beim Carcinoma ventriculi1. Dtsch Med Wochenschr 1895; 21(05): 73-75.

112. Heinemann P and Ecker E, A study of the Boas-Oppler bacillus. J Bacteriol 1916; 1(4): 435.

113. Marshall B and Warren JR, Unidentified curved bacilli in the stomach of patients with gastritis and peptic ulceration. Lancet 1984; 323(8390): 1311-1315.

114. Sjomina O, Pavlova J, Niv Y, et al., Epidemiology of Helicobacter pylori infection. Helicobacter 2018; 23: e12514.

115. Venerito M, Vasapolli R, Rokkas T, et al., Gastric cancer: epidemiology, prevention, and therapy. Helicobacter 2018; 23: e12518.

116. Herrera V and Parsonnet J, Helicobacter pylori and gastric adenocarcinoma. Clin Microbiol Infect 2009; 15(11): 971-976.

117. Mentis A-FA, Boziki M, Grigoriadis N, et al., Helicobacter pylori infection and gastric cancer biology: tempering a double-edged sword. Cell Mol Life Sci 2019; 76(13): 2477-2486.

118. Cover TL, Krishna US, Israel DA, et al., Induction of gastric epithelial cell apoptosis by Helicobacter pylori vacuolating cytotoxin. Cancer Res 2003; 63(5): 951-957.

119. Trounson A and DeWitt ND, Pluripotent stem cells progressing to the clinic. Nature reviews Molecular cell biology 2016; 17(3): 194.

120. Piazuelo MB and Correa P, Gastric cancer: overview. Colomb Med 2013; 44(3): 192-201. 
121. Piazuelo MB, Camargo MC, Mera RM, et al., Gastric intestinal metaplasia type III and prospective risk of gastric cancer in colombia. Gastroenterology 2017; 152(5): S473.

122. Wroblewski LE and Peek RM, Helicobacter pylori in gastric carcinogenesis: mechanisms. Gastroenterol Clin North Am 2013; 42(2): 285-298.

123. Sicinschi L, Correa P, Peek R, et al., CagA C-terminal variations in Helicobacter pylori strains from Colombian patients with gastric precancerous lesions. Clin Microbiol Infect 2010; 16(4): 369-378.

124. Sougleri IS, Papadakos KS, Zadik MP, et al., Helicobacter pylori CagA protein induces factors involved in the epithelial to mesenchymal transition (EMT) in infected gastric epithelial cells in an EPIYA-phosphorylationdependent manner. FEBS journal 2016; 283(2): 206-220.

125. Oertli M, Sundquist M, Hitzler I, et al., DC-derived IL-18 drives Treg differentiation, murine Helicobacter pylorispecific immune tolerance, and asthma protection. J Clin Invest 2012; 122(3): 1082-1096.

126. Sáenz JB and Mills JC, Acid and the basis for cellular plasticity and reprogramming in gastric repair and cancer. Nat Rev Gastroenterol Hepatol 2018; 15(5): 257.

127. Brabletz T, Kalluri R, Nieto MA, et al., EMT in cancer. Nat Rev Cancer 2018; 18(2): 128.

128. De Martel C, Ferlay J, Franceschi S, et al., Global burden of cancers attributable to infections in 2008: a review and synthetic analysis. Lancet Oncol 2012; 13(6): 607-615.

129. Lertpiriyapong K, Whary MT, Muthupalani S, et al., Gastric colonisation with a restricted commensal microbiota replicates the promotion of neoplastic lesions by diverse intestinal microbiota in the Helicobacter pylori INS-GAS mouse model of gastric carcinogenesis. Gut 2014; 63(1): 54-63.

130. Thomson MJ, Pritchard DM, Boxall SA, et al., Gastric Helicobacter infection induces iron deficiency in the INSGAS mouse. PLoS One 2012; 7(11).

131. Gu S, Chen Y, Zhang X, et al., Identification of key taxa that favor intestinal colonization of Clostridium difficile in an adult Chinese population. Microb Infect 2016; 18(1): 30-38.

132. Loo VG, Bourgault A-M, Poirier L, et al., Host and pathogen factors for Clostridium difficile infection and colonization. N Engl J Med 2011; 365(18): 1693-1703.

133. Shivashankar R, Khanna S, Kammer PP, et al., Clinical predictors of recurrent Clostridium difficile infection in out-patients. Aliment Pharmacol Ther 2014; 40(5): 518-522.

134. Sorg JA and Sonenshein AL, Bile salts and glycine as cogerminants for Clostridium difficile spores. J Bacteriol 2008; 190(7): 2505-2512.

135. Kang JD, Myers CJ, Harris SC, et al., Bile acid $7 \alpha$-dehydroxylating gut bacteria secrete antibiotics that inhibit Clostridium difficile: role of secondary bile acids. Cell Chem Biol 2019; 26(1): 27-34. e4.

136. Weingarden AR, Chen C, Bobr A, et al., Microbiota transplantation restores normal fecal bile acid composition in recurrent Clostridium difficile infection. Am J Physiol Gastrointest Liver Physiol 2014; 306(4): G310-G319.

137. Buffie CG, Bucci V, Stein RR, et al., Precision microbiome reconstitution restores bile acid mediated resistance to Clostridium difficile. Nature 2015; 517(7533): 205-208.

138. Delaney M, History of HAART-the true story of how effective multi-drug therapy was developed for treatment of HIV disease. Retrovirology 2006; 3(1): S6.

139. Neuhaus J, Jacobs Jr DR, Baker JV, et al., Markers of inflammation, coagulation, and renal function are elevated in adults with HIV infection. J Infect Dis 2010; 201(12): 1788-1795.

140. Kuller LH, Tracy R, Belloso W, et al., Inflammatory and coagulation biomarkers and mortality in patients with HIV infection. PLoS Med 2008; 5(10). 
141. Deeks SG, Kitchen CM, Liu L, et al., Immune activation set point during early HIV infection predicts subsequent CD4+ T-cell changes independent of viral load. Blood 2004; 104(4): 942-947.

142. Tang WW, Wang Z, Levison BS, et al., Intestinal microbial metabolism of phosphatidylcholine and cardiovascular risk. N Engl J Med 2013; 368(17): 1575-1584.

143. Alejos B, Hernando V, López-Aldeguer J, et al., Overall and cause-specific mortality in HIV-positive subjects compared to the general population. J Int AIDS Soc 2014; 17.

144. Li Q, Duan L, Estes JD, et al., Peak SIV replication in resting memory CD4+ T cells depletes gut lamina propria CD4+ T cells. Nature 2005; 434(7037): 1148-1152.

145. Eyerich K, Dimartino V, and Cavani A, IL-17 and IL-22 in immunity: Driving protection and pathology. Eur J Immunol 2017; 47(4): 607-614.

146. Vujkovic-Cvijin I, Dunham RM, Iwai S, et al., Dysbiosis of the gut microbiota is associated with HIV disease progression and tryptophan catabolism. Sci Transl Med 2013; 5(193): 193ra91-193ra91.

147. Dillon S, Lee E, Kotter C, et al., An altered intestinal mucosal microbiome in HIV-1 infection is associated with mucosal and systemic immune activation and endotoxemia. Mucosal Immunol 2014; 7(4): 983-994.

148. Nowak P, Troseid M, Avershina E, et al., Gut microbiota diversity predicts immune status in HIV-1 infection. AIDS 2015; 29(18): 2409-2418.

149. Ling Z, Jin C, Xie T, et al., Alterations in the fecal microbiota of patients with HIV-1 infection: an observational study in a Chinese population. Sci Rep 2016; 6(1): 1-12.

150. Telesford KM, Yan W, Ochoa-Reparaz J, et al., A commensal symbiotic factor derived from Bacteroides fragilis promotes human CD39+ Foxp3+ T cells and Treg function. Gut microbes 2015; 6(4): 234-242.

151. Brenchley JM, Price DA, Schacker TW, et al., Microbial translocation is a cause of systemic immune activation in chronic HIV infection. Nat Med 2006; 12(12): 1365-1371.

152. Paquin-Proulx D, Ching C, Vujkovic-Cvijin I, et al., Bacteroides are associated with GALT iNKT cell function and reduction of microbial translocation in HIV-1 infection. Mucosal Immunol 2017; 10(1): 69-78.

153. Lathrop SK, Bloom SM, Rao SM, et al., Peripheral education of the immune system by colonic commensal microbiota. Nature 2011; 478(7368): 250-254.

154. Faith JJ, Ahern PP, Ridaura VK, et al., Identifying gut microbe-host phenotype relationships using combinatorial communities in gnotobiotic mice. Sci Transl Med 2014; 6(220): 220ra11-220ra11.

155. Garrett WS, Lord GM, Punit S, et al., Communicable ulcerative colitis induced by T-bet deficiency in the innate immune system. Cell 2007; 131(1): 33-45.

156. Dandekar S, George MD, and Bäumler AJ, Th17 cells, HIV and the gut mucosal barrier. Curr Opin HIV AIDS 2010; 5(2): 173-178.

157. Estes JD, Harris LD, Klatt NR, et al., Damaged intestinal epithelial integrity linked to microbial translocation in pathogenic simian immunodeficiency virus infections. PLoS Pathog 2010; 6(8).

158. Neff CP, Krueger O, Xiong K, et al., Fecal microbiota composition drives immune activation in HIV-infected individuals. EBioMedicine 2018; 30: 192-202.

159. Dubourg G, Surenaud M, Lévy Y, et al., Microbiome of HIV-infected people. Microb Pathog 2017; 106: 85-93.

160. Greiner TU and Bäckhed F, Microbial regulation of GLP-1 and L-cell biology. Mol Metab 2016; 5(9): 753-758.

161. Rajala MW, Patterson CM, Opp JS, et al., Leptin acts independently of food intake to modulate gut microbial composition in male mice. Endocrinology 2014; 155(3): 748-757.

162. Davis CD, The gut microbiome and its role in obesity. Nutr Today 2016; 51(4): 167. 
163. Rastelli M, Knauf C, and Cani PD, Gut microbes and health: a focus on the mechanisms linking microbes, obesity, and related disorders. Obesity 2018; 26(5): 792-800.

164. Turnbaugh PJ, Hamady M, Yatsunenko T, et al., A core gut microbiome in obese and lean twins. Nature 2009; 457(7228): 480-484.

165. Kasai C, Sugimoto K, Moritani I, et al., Comparison of the gut microbiota composition between obese and nonobese individuals in a Japanese population, as analyzed by terminal restriction fragment length polymorphism and next-generation sequencing. BMC Gastroenterol 2015; 15(1): 100.

166. Ley RE, Bäckhed F, Turnbaugh P, et al., Obesity alters gut microbial ecology. Proc Natl Acad Sci 2005; 102(31): 11070-11075.

167. Turnbaugh PJ, Ley RE, Mahowald MA, et al., An obesity-associated gut microbiome with increased capacity for energy harvest. Nature 2006; 444(7122): 1027.

168. Ley RE, Turnbaugh PJ, Klein S, et al., Human gut microbes associated with obesity. Nature 2006; 444(7122): 1022-1023.

169. Tremaroli V, Karlsson F, Werling M, et al., Roux-en-Y gastric bypass and vertical banded gastroplasty induce long-term changes on the human gut microbiome contributing to fat mass regulation. Cell Metab 2015; 22(2): 228-238.

170. Palleja A, Kashani A, Allin KH, et al., Roux-en-Y gastric bypass surgery of morbidly obese patients induces swift and persistent changes of the individual gut microbiota. Genome Med 2016; 8(1): 67.

171. Shah S, Crosslin D, Haynes C, et al., Branched-chain amino acid levels are associated with improvement in insulin resistance with weight loss. Diabetologia 2012; 55(2): 321-330.

172. Solon-Biet SM, Cogger VC, Pulpitel T, et al., Branched-chain amino acids impact health and lifespan indirectly via amino acid balance and appetite control. Nat Metab 2019; 1(5): 532.

173. Ridaura VK, Faith JJ, Rey FE, et al., Gut microbiota from twins discordant for obesity modulate metabolism in mice. Science 2013; 341(6150): 1241214.

174. Bäckhed F, Ding H, Wang T, et al., The gut microbiota as an environmental factor that regulates fat storage. Proc Natl Acad Sci 2004; 101(44): 15718-15723.

175. Bäckhed F, Ley RE, Sonnenburg JL, et al., Host-bacterial mutualism in the human intestine. Science 2005; 307(5717): 1915-1920.

176. Fonseca VA, Defining and characterizing the progression of type 2 diabetes. Diabetes Care 2009; 32(suppl 2): S151-S156.

177. Musso G, Gambino R, and Cassader M, Interactions between gut microbiota and host metabolism predisposing to obesity and diabetes. Annu Rev Med 2011; 62: 361-380.

178. Wen L and Duffy A, Factors influencing the gut microbiota, inflammation, and type 2 diabetes. J Nutr 2017; 147(7): 1468S-1475S.

179. Cani PD, Osto M, Geurts L, et al., Involvement of gut microbiota in the development of low-grade inflammation and type 2 diabetes associated with obesity. Gut Microbes 2012; 3(4): 279-288.

180. Sanz Y, Rastmanesh R, and Agostonic C, Understanding the role of gut microbes and probiotics in obesity: how far are we? Pharmacol Res 2013; 69(1): 144-155.

181. Gurung M, Li Z, You H, et al., Role of gut microbiota in type 2 diabetes pathophysiology. EBioMedicine 2020; 51: 102590 .

182. Gao R, Zhu C, Li H, et al., Dysbiosis signatures of gut microbiota along the sequence from healthy, young patients to those with overweight and obesity. Obesity 2018; 26(2): 351-361. 
183. Candela M, Biagi E, Soverini M, et al., Modulation of gut microbiota dysbioses in type 2 diabetic patients by macrobiotic Ma-Pi 2 diet. Br J Nutr 2016; 116(1): 80-93.

184. Le TKC, Hosaka T, Nguyen TT, et al., Bifidobacterium species lower serum glucose, increase expressions of insulin signaling proteins, and improve adipokine profile in diabetic mice. Biomed Res 2015; 36(1): 63-70.

185. Moya-Perez A, Neef A, and Sanz Y, Bifidobacterium pseudocatenulatum CECT 7765 reduces obesity-associated inflammation by restoring the lymphocyte-macrophage balance and gut microbiota structure in high-fat diet-fed mice. PLoS One 2015; 10(7).

186. Liu W-C, Yang M-C, Wu Y-Y, et al., Lactobacillus plantarum reverse diabetes-induced Fmo3 and ICAM expression in mice through enteric dysbiosis-related c-Jun NH2-terminal kinase pathways. PLoS One 2018; 13(5).

187. Tian P, Li B, He C, et al., Antidiabetic (type 2) effects of Lactobacillus G15 and Q14 in rats through regulation of intestinal permeability and microbiota. Food Funct 2016; 7(9): 3789-3797.

188. Kinoshita M, Suzuki Y, and Saito Y, Butyrate reduces colonic paracellular permeability by enhancing PPAR $\gamma$ activation. Biochem Biophys Res Commun 2002; 293(2): 827-831.

189. Qin J, Li Y, Cai Z, et al., A metagenome-wide association study of gut microbiota in type 2 diabetes. Nature 2012; 490(7418): 55-60.

190. Larsen N, Vogensen FK, Van Den Berg FW, et al., Gut microbiota in human adults with type 2 diabetes differs from non-diabetic adults. PLoS One 2010; 5(2).

191. Sagar NM, Cree IA, Covington JA, et al., The interplay of the gut microbiome, bile acids, and volatile organic compounds. Gastroenterol Res Pract 2015; 2015.

192. Hylemon PB, Zhou H, Pandak WM, et al., Bile acids as regulatory molecules. J Lipid Res 2009; 50(8): 15091520 .

193. Sonne DP, Hansen M, and Knop FK, Bile acid sequestrants in type 2 diabetes: potential effects on GLP1 secretion. Eur J Endocrinol 2014; 171(2): R47-R65.

194. Sanna S, van Zuydam NR, Mahajan A, et al., Causal relationships among the gut microbiome, short-chain fatty acids and metabolic diseases. Nat Genet 2019; 51(4): 600-605.

195. Chambers ES, Viardot A, Psichas A, et al., Effects of targeted delivery of propionate to the human colon on appetite regulation, body weight maintenance and adiposity in overweight adults. Gut 2015; 64(11): 1744-1754.

196. Segal LN and Blaser MJ, A brave new world: the lung microbiota in an era of change. Ann Am Thorac Soc 2014; 11(Supplement 1): S21-S27.

197. Charlson ES, Bittinger K, Haas AR, et al., Topographical continuity of bacterial populations in the healthy human respiratory tract. Am J Respir Crit Care Med 2011; 184(8): 957-963.

198. Lal CV, Travers C, Aghai ZH, et al., The airway microbiome at birth. Sci Rep 2016; 6: 31023.

199. Gleeson K, Maxwell SL, and Eggli DF, Quantitative aspiration during sleep in normal subjects. Chest 1997; 111(5): 1266-1272.

200. Dickson RP, Erb-Downward JR, Freeman CM, et al., Bacterial topography of the healthy human lower respiratory tract. MBio 2017; 8(1): e02287-16.

201. Schuijt TJ, Lankelma JM, Scicluna BP, et al., The gut microbiota plays a protective role in the host defence against pneumococcal pneumonia. Gut 2016; 65(4): 575-583.

202. Adcock IM, Caramori G, and Chung KF, New targets for drug development in asthma. Lancet 2008; 372(9643): 1073-1087.

203. Huang YJ, Nelson CE, Brodie EL, et al., Airway microbiota and bronchial hyperresponsiveness in patients with suboptimally controlled asthma. J Allergy Clin Immunol 2011; 127(2): 372-381. e3. 
204. Teo SM, Mok D, Pham K, et al., The infant nasopharyngeal microbiome impacts severity of lower respiratory infection and risk of asthma development. Cell Host Microbe 2015; 17(5): 704-715.

205. Arrieta M-C, Stiemsma LT, Dimitriu PA, et al., Early infancy microbial and metabolic alterations affect risk of childhood asthma. Sci Transl Med 2015; 7(307): 307ra152-307ra152.

206. van Nimwegen FA, Penders J, Stobberingh EE, et al., Mode and place of delivery, gastrointestinal microbiota, and their influence on asthma and atopy. J Allergy Clin Immunol 2011; 128(5): 948-955. e3.

207. Dang AT and Marsland BJ, Microbes, metabolites, and the gut-lung axis. Mucosal Immunol 2019; 12(4): 843850 .

208. Tulic M, Piche T, and Verhasselt V, Lung-gut cross-talk: evidence, mechanisms and implications for the mucosal inflammatory diseases. Clin Exp Allergy 2016; 46(4): 519-528.

209. Metsälä J, Lundqvist A, Virta L, et al., Prenatal and post-natal exposure to antibiotics and risk of asthma in childhood. Clin Exp Allergy 2015; 45(1): 137-145.

210. Marra F, Marra CA, Richardson K, et al., Antibiotic use in children is associated with increased risk of asthma. Pediatrics 2009; 123(3): 1003-1010.

211. Goleva E, Jackson LP, Harris JK, et al., The effects of airway microbiome on corticosteroid responsiveness in asthma. Am J Respir Crit Care Med 2013; 188(10): 1193-1201.

212. Bisgaard H, Hermansen MN, Buchvald F, et al., Childhood asthma after bacterial colonization of the airway in neonates. N Engl J Med 2007; 357(15): 1487-1495.

213. Halnes I, Baines KJ, Berthon BS, et al., Soluble fibre meal challenge reduces airway inflammation and expression of GPR43 and GPR41 in asthma. Nutrients 2017; 9(1): 57.

214. Ferraro A and Kilman J, Experimental toxic approach to mental diseases. Psychiatr Q 1933; 7(1): 115-153.

215. Rhee SH, Pothoulakis C, and Mayer EA, Principles and clinical implications of the brain-gut-enteric microbiota axis. Nat Rev Gastroenterol Hepatol 2009; 6(5): 306.

216. Bravo JA, Forsythe P, Chew MV, et al., Ingestion of Lactobacillus strain regulates emotional behavior and central GABA receptor expression in a mouse via the vagus nerve. Proc Natl Acad Sci 2011; 108(38): 16050-16055.

217. Rieder R, Wisniewski PJ, Alderman BL, et al., Microbes and mental health: a review. Brain Behav Immun 2017; 66: 9-17.

218. Braniste V, Al-Asmakh M, Kowal C, et al., The gut microbiota influences blood-brain barrier permeability in mice. Sci Transl Med 2014; 6(263): 263ra158-263ra158.

219. Sherwin E, Sandhu KV, Dinan TG, et al., May the force be with you: the light and dark sides of the microbiotagut-brain axis in neuropsychiatry. CNS drugs 2016; 30(11): 1019-1041.

220. Forsythe P and Kunze WA, Voices from within: gut microbes and the CNS. Cell Mol Life Sci 2013; $70(1)$ : $55-$ 69.

221. Rawdin B, Mellon S, Dhabhar F, et al., Dysregulated relationship of inflammation and oxidative stress in major depression. Brain Behav Immun 2013; 31: 143-152.

222. Maes M, Kubera M, Leunis JC, et al., In depression, bacterial translocation may drive inflammatory responses, oxidative and nitrosative stress (O\&NS), and autoimmune responses directed against O\&NS-damaged neoepitopes. Acta Psychiatr Scand 2013; 127(5): 344-354.

223. Boulanger LM, Immune proteins in brain development and synaptic plasticity. Neuron 2009; 64(1): 93-109.

224. de Magistris L, Familiari V, Pascotto A, et al., Alterations of the intestinal barrier in patients with autism spectrum disorders and in their first-degree relatives. J Pediatr Gastroenterol Nutr 2010; 51(4): 418-424. 
225. Dinan T, Borre Y, and Cryan J, Genomics of schizophrenia: time to consider the gut microbiome? Mol Psychiatry 2014; 19(12): 1252-1257.

226. Lyte M, Probiotics function mechanistically as delivery vehicles for neuroactive compounds: microbial endocrinology in the design and use of probiotics. Bioessays 2011; 33(8): 574-581.

227. Matsumoto M, Kibe R, Ooga T, et al., Cerebral low-molecular metabolites influenced by intestinal microbiota: a pilot study. Front Syst Neurosci 2013; 7: 9.

228. Clarke G, Grenham S, Scully P, et al., The microbiome-gut-brain axis during early life regulates the hippocampal serotonergic system in a sex-dependent manner. Mol Psychiatry 2013; 18(6): 666-673.

229. Association AAP, American Psychiatric Association DSM-5 Task Force. Diagnostic and Statistical Manual of Mental Disorders (DSM-5).

230. Kohane IS, McMurry A, Weber G, et al., The co-morbidity burden of children and young adults with autism spectrum disorders. PLoS One 2012; 7(4).

231. Iossifov I, Levy D, Allen J, et al., Low load for disruptive mutations in autism genes and their biased transmission. Proc Natl Acad Sci 2015; 112(41): E5600-E5607.

232. Gaugler T, Klei L, Sanders SJ, et al., Most genetic risk for autism resides with common variation. Nat Genet 2014; 46(8): 881 .

233. Molloy CA and Manning-Courtney P, Prevalence of chronic gastrointestinal symptoms in children with autism and autistic spectrum disorders. Autism 2003; 7(2): 165-171.

234. Ming X, Brimacombe M, Chaaban J, et al., Autism spectrum disorders: concurrent clinical disorders. J Child Neurol 2008; 23(1): 6-13.

235. Kang D-W, Adams JB, Gregory AC, et al., Microbiota Transfer Therapy alters gut ecosystem and improves gastrointestinal and autism symptoms: an open-label study. Microbiome 2017; 5(1): 10.

236. Emanuele E, Orsi P, Boso M, et al., Low-grade endotoxemia in patients with severe autism. Neurosci Lett 2010; 471(3): 162-165.

237. Finegold SM, Molitoris D, Song Y, et al., Gastrointestinal microflora studies in late-onset autism. Clin Infect Dis 2002; 35(Supplement_1): S6-S16.

238. Song Y, Liu C, and Finegold SM, Real-time PCR quantitation of clostridia in feces of autistic children. Appl Environ Microbiol 2004; 70(11): 6459-6465.

239. Parracho HM, Bingham MO, Gibson GR, et al., Differences between the gut microflora of children with autistic spectrum disorders and that of healthy children. J Med Microbiol 2005; 54(10): 987-991.

240. Finegold SM, Dowd SE, Gontcharova V, et al., Pyrosequencing study of fecal microflora of autistic and control children. Anaerobe 2010; 16(4): 444-453.

241. Ho LKH, Tong VJW, Syn N, et al., Gut microbiota changes in children with autism spectrum disorder: a systematic review. Gut Pathog 2020; 12(1): 6.

242. Wimberley T, Agerbo E, Pedersen CB, et al., Otitis media, antibiotics, and risk of autism spectrum disorder. Autism Res 2018; 11(10): 1432-1440.

243. Bolte E, Autism and Clostridium tetani. Med Hypotheses 1998; 51(2): 133-144.

244. Pardo CA, Buckley A, Thurm A, et al., A pilot open-label trial of minocycline in patients with autism and regressive features. J Neurodev Disord 2013; 5(1): 9.

245. Altieri L, Neri C, Sacco R, et al., Urinary p-cresol is elevated in small children with severe autism spectrum disorder. Biomarkers 2011; 16(3): 252-260. 
246. Iovene MR, Bombace F, Maresca R, et al., Intestinal dysbiosis and yeast isolation in stool of subjects with autism spectrum disorders. Mycopathologia 2017; 182(3-4): 349-363.

247. Sandler RH, Finegold SM, Bolte ER, et al., Short-term benefit from oral vancomycin treatment of regressiveonset autism. J Child Neurol 2000; 15(7): 429-435.

248. Reichelt $\mathrm{K}$ and Knivsberg A, The possibility and probability of a gut-to-brain connection in autism. Ann Clin Psychiatry 2009; 21(4): 205-11.

249. Komura J, Tamai I, Senmaru M, et al., Brain-to-blood active transport of $\beta$-alanine across the blood-brain barrier. FEBS Lett 1997; 400(1): 131-135.

250. Ishiwari K, Mingote S, Correa M, et al., The GABA uptake inhibitor $\beta$-alanine reduces pilocarpine-induced tremor and increases extracellular GABA in substantia nigra pars reticulata as measured by microdialysis. J Neurosci Methods 2004; 140(1-2): 39-46.

251. Burrus CJ, A biochemical rationale for the interaction between gastrointestinal yeast and autism. Med Hypotheses 2012; 79(6): 784-785.

252. Aldred S, Moore KM, Fitzgerald M, et al., Plasma amino acid levels in children with autism and their families. J Autism Dev Disord 2003; 33(1): 93-97.

253. Ding HT, Taur Y, and Walkup JT, Gut microbiota and autism: key concepts and findings. J Autism Dev Disord 2017; 47(2): 480-489.

254. Doshi-Velez F, Ge Y, and Kohane I, Comorbidity clusters in autism spectrum disorders: an electronic health record time-series analysis. Pediatrics 2014; 133(1): e54-e63.

255. Ashwood P, Krakowiak P, Hertz-Picciotto I, et al., Elevated plasma cytokines in autism spectrum disorders provide evidence of immune dysfunction and are associated with impaired behavioral outcome. Brain Behav Immun 2011; 25(1): 40-45.

256. Onore C, Careaga M, and Ashwood P, The role of immune dysfunction in the pathophysiology of autism. Brain Behav Immun 2012; 26(3): 383-392.

257. Jagust W, Imaging the evolution and pathophysiology of Alzheimer disease. Nat Rev Neurosci 2018; 19(11): 687 700.

258. Angelucci F, Cechova K, Amlerova J, et al., Antibiotics, gut microbiota, and Alzheimer's disease. J Neuroinflammation 2019; 16(1): 108.

259. Lee L-H, Ser H-L, Khan TM, et al., Dissecting the gut and brain: potential links between gut microbiota in development of alzheimer's disease? Gut 2018.

260. Lach G, Schellekens H, Dinan TG, et al., Anxiety, depression, and the microbiome: a role for gut peptides. Neurotherapeutics 2018; 15(1): 36-59.

261. Cai Z, Hussain MD, and Yan L-J, Microglia, neuroinflammation, and beta-amyloid protein in Alzheimer's disease. Int J Neurosci 2014; 124(5): 307-321.

262. Harach T, Marungruang N, Duthilleul N, et al., Reduction of Abeta amyloid pathology in APPPS1 transgenic mice in the absence of gut microbiota. Sci Rep 2017; 7: 41802.

263. Bu XL, Yao XQ, Jiao SS, et al., A study on the association between infectious burden and A lzheimer's disease. Eur J Neurol 2015; 22(12): 1519-1525.

264. Pisa D, Alonso R, Fernández-Fernández AM, et al., Polymicrobial infections in brain tissue from Alzheimer's disease patients. Sci Rep 2017; 7(1): 1-14.

265. Cattaneo A, Cattane N, Galluzzi S, et al., Association of brain amyloidosis with pro-inflammatory gut bacterial taxa and peripheral inflammation markers in cognitively impaired elderly. Neurobiol Aging 2017; 49: 60-68. 
266. Zhao Y, Jaber V, and Lukiw WJ, Secretory products of the human GI tract microbiome and their potential impact on Alzheimer's disease (AD): detection of lipopolysaccharide (LPS) in AD hippocampus. Front Cell Infect Microbiol 2017; 7: 318.

267. Wang T, Hu X, Liang S, et al., Lactobacillus fermentum NS9 restores the antibiotic induced physiological and psychological abnormalities in rats. Beneficial microbes 2015; 6(5): 707-717.

268. Choi $\mathrm{HH}$ and Cho Y-S, Fecal microbiota transplantation: current applications, effectiveness, and future perspectives. Clin Endosc 2016; 49(3): 257.

269. Hsiao EY, McBride SW, Hsien S, et al., Microbiota modulate behavioral and physiological abnormalities associated with neurodevelopmental disorders. Cell 2013; 155(7): 1451-1463.

270. Li H, Sun J, Du J, et al., Clostridium butyricum exerts a neuroprotective effect in a mouse model of traumatic brain injury via the gut-brain axis. Neurogastroenterol Motil 2018; 30(5): e13260.

271. Caracciolo B, Xu W, Collins S, et al., Cognitive decline, dietary factors and gut-brain interactions. Mech Ageing Dev 2014; 136: 59-69.

272. Claesson MJ, Jeffery IB, Conde S, et al., Gut microbiota composition correlates with diet and health in the elderly. Nature 2012; 488(7410): 178-184.

273. Franceschi C, Bonafè M, Valensin S, et al., Inflamm-aging: an evolutionary perspective on immunosenescence. Ann N Y Acad Sci 2000; 908(1): 244-254.

274. Anukam KC and Reid G, Probiotics: 100 years (1907-2007) after Elie Metchnikoff's observation, in Communicating current research and educational topics and trends in applied microbiology, M.-v. A, Editor. 2007, Fromatex.org, Spain. p. 466-474.

275. McGovern PE, Uncorking the past: the quest for wine, beer, and other alcoholic beverages. 2009: Univ of California Press.

276. Klaenhammer TR, Kleerebezem M, Kopp MV, et al., The impact of probiotics and prebiotics on the immune system. Nat Rev Immunol 2012; 12(10): 728-734.

277. Childs CE, Röytiö H, Alhoniemi E, et al., Xylo-oligosaccharides alone or in synbiotic combination with Bifidobacterium animalis subsp. lactis induce bifidogenesis and modulate markers of immune function in healthy adults: a double-blind, placebo-controlled, randomised, factorial cross-over study. Br J Nutr 2014; 111(11): 1945 1956.

278. Fedorak RN and Madsen KL, Probiotics and prebiotics in gastrointestinal disorders. Curr Opin Gastroenterol 2004; 20(2): 146-155.

279. Marteau P and Boutron-Ruault M, Nutritional advantages of probiotics and prebiotics. Br J Nutr 2002; 87(S2): S153-S157.

280. Meijer BJ and Dieleman LA, Probiotics in the treatment of human inflammatory bowel diseases: update 2011. J Clin Gastroenterol 2011; 45: S139-S144.

281. Veerappan GR, Betteridge J, and Young PE, Probiotics for the treatment of inflammatory bowel disease. Curr Gastroenterol Rep 2012; 14(4): 324-333.

282. Waligora-Dupriet A-J and Butel M-J, Microbiota and allergy: from dysbiosis to probiotics, in Allergic diseaseshighlights in the clinic, mechanisms and treatment, C. Pereira, Editor. 2012, InTech: Rijeka, Croatia. p. 413-434.

283. Pelucchi C, Chatenoud L, Turati F, et al., Probiotics supplementation during pregnancy or infancy for the prevention of atopic dermatitis: a meta-analysis. Epidemiology 2012: 402-414.

284. Rowland I, Gibson G, Heinken A, et al., Gut microbiota functions: metabolism of nutrients and other food components. Eur J Nutr 2018; 57(1): 1-24. 
285. Tsai Y-L, Lin T-L, Chang C-J, et al., Probiotics, prebiotics and amelioration of diseases. J Biomed Sci 2019; 26(1): $1-8$.

286. Fijan S, Microorganisms with claimed probiotic properties: an overview of recent literature. Int J Environ Res Public Health 2014; 11(5): 4745-4767.

287. Costeloe K, Hardy P, Juszczak E, et al., Bifidobacterium breve BBG-001 in very preterm infants: a randomised controlled phase 3 trial. Lancet 2016; 387(10019): 649-660.

288. Panigrahi P, Parida S, Nanda NC, et al., A randomized synbiotic trial to prevent sepsis among infants in rural India. Nature 2017; 548(7668): 407-412.

289. Maldonado-Gómez MX, Martínez I, Bottacini F, et al., Stable engraftment of Bifidobacterium longum AH1206 in the human gut depends on individualized features of the resident microbiome. Cell Host Microbe 2016; 20(4): 515-526.

290. Gogineni VK, Morrow LE, Gregory PJ, et al., Probiotics: history and evolution. J Infect Dis Prevent Med 2013; 1(2): $1-7$.

291. Petersen A, Heegaard PM, Pedersen AL, et al., Some putative prebiotics increase the severity of Salmonella entericaserovar Typhimurium infection in mice. BMC Microbiol 2009; 9(1): 245.

292. Bongers A and van den Heuvel EG, Prebiotics and the bioavailability of minerals and trace elements. Food Rev Int 2003; 19(4): 397-422.

293. Doron S and Snydman DR, Risk and safety of probiotics. Clin Infect Dis 2015; 60(suppl_2): S129-S134.

294. Cruchet S, Furnes R, Maruy A, et al., The use of probiotics in pediatric gastroenterology: a review of the literature and recommendations by Latin-American experts. Pediatr Drugs 2015; 17(3): 199-216.

295. Cameron D, Hock QS, Musal Kadim NM, et al., Probiotics for gastrointestinal disorders: proposed recommendations for children of the Asia-Pacific region. World J Gastroenterol 2017; 23(45): 7952.

296. Reid G, Disentangling what we know about microbes and mental health. Front Endocrinol (Lausanne) $2019 ; 10$.

297. Dhingra D, Michael M, Rajput H, et al., Dietary fibre in foods: a review. J Food Sci Technol 2012; 49(3): 255266.

298. Lozupone CA, Stombaugh JI, Gordon JI, et al., Diversity, stability and resilience of the human gut microbiota. Nature 2012; 489(7415): 220-230.

299. Elleuch M, Bedigian D, Roiseux O, et al., Dietary fibre and fibre-rich by-products of food processing: Characterisation, technological functionality and commercial applications: A review. Food Chem 2011; 124(2): 411-421.

300. McRorie JW and Fahey GC, A review of gastrointestinal physiology and the mechanisms underlying the health benefits of dietary fiber: matching an effective fiber with specific patient needs. Clin Nurs Stud 2013; 1(4): 8292.

301. Gibson GR, Scott KP, Rastall RA, et al., Dietary prebiotics: current status and new definition. Food Sci Tech Bull Funct Foods 2010; 7(1): 1-19.

302. Bindels LB, Delzenne NM, Cani PD, et al., Towards a more comprehensive concept for prebiotics. Nat Rev Gastroenterol Hepatol 2015; 12(5): 303.

303. David LA, Maurice CF, Carmody RN, et al., Diet rapidly and reproducibly alters the human gut microbiome. Nature 2014; 505(7484): 559-563.

304. Segata N, Gut microbiome: westernization and the disappearance of intestinal diversity. Curr Biol 2015; 25(14): R611-R613. 
305. Sonnenburg ED, Smits SA, Tikhonov M, et al., Diet-induced extinctions in the gut microbiota compound over generations. Nature 2016; 529(7585): 212-215.

306. Cotillard A, Kennedy SP, Kong LC, et al., Dietary intervention impact on gut microbial gene richness. Nature 2013; 500(7464): 585-588.

307. Wollowski I, Rechkemmer G, and Pool-Zobel BL, Protective role of probiotics and prebiotics in colon cancer. Am J Clin Nutr 2001; 73(2): 451s-455s.

308. Viladomiu M, Hontecillas R, Yuan L, et al., Nutritional protective mechanisms against gut inflammation. J Nutr Biochem 2013; 24(6): 929-939.

309. Casellas F, Borruel N, Torrejon A, et al., Oral oligofructose-enriched inulin supplementation in acute ulcerative colitis is well tolerated and associated with lowered faecal calprotectin. Aliment Pharmacol Ther 2007; 25(9): 1061-1067.

310. Schieber A, Stintzing FC, and Carle R, By-products of plant food processing as a source of functional compounds—recent developments. Trends Food Sci Technol 2001; 12(11): 401-413.

311. Moro G, Arslanoglu S, Stahl B, et al., A mixture of prebiotic oligosaccharides reduces the incidence of atopic dermatitis during the first six months of age. Arch Dis Child 2006; 91(10): 814-819.

312. Ivakhnenko OS and Nyankovskyy SL, Effect of the specific infant formula mixture of oligosaccharides on local immunity and development of allergic and infectious disease in young children: Randomized study. Pediatr Pol 2013; 88(5): 398-404.

313. Arslanoglu S, Moro G, Boehm G, et al., Early Neutral Prebiotic Oligosaccharide Supplentation reduces the incidence of some allergic manifestations in the first 5 years of life. J Biol Regul Homeost Agents 2012; 26: 4959.

314. Mitchell CM, Davy BM, Halliday TM, et al., The effect of prebiotic supplementation with inulin on cardiometabolic health: Rationale, design, and methods of a controlled feeding efficacy trial in adults at risk of type 2 diabetes. Contemp Clin Trials 2015; 45: 328-337.

315. Healey G, Murphy R, Butts C, et al., Habitual dietary fibre intake influences gut microbiota response to an inulintype fructan prebiotic: a randomised, double-blind, placebo-controlled, cross-over, human intervention study. $\mathrm{Br}$ J Nutr 2018; 119(2): 176-189.

316. Dey M, Toward a personalized approach in prebiotics research. Nutrients 2017; 9(2): 92.

317. Davani-Davari D, Negahdaripour M, Karimzadeh I, et al., Prebiotics: definition, types, sources, mechanisms, and clinical applications. Foods 2019; 8(3): 92.

318. Svensson U and Håkansson J, Safety of Food and Beverages: Safety of Probiotics and Prebiotics. 2014.

319. Eiseman B, Silen W, Bascom G, et al., Fecal enema as an adjunct in the treatment of pseudomembranous enterocolitis. Surgery 1958; 44(5): 854-859.

320. Fischer M, Sipe B, Cheng Y-W, et al., Fecal microbiota transplant in severe and severe-complicated Clostridium difficile: a promising treatment approach. Gut Microbes 2017; 8(3): 289-302.

321. Cammarota G, Ianiro G, and Gasbarrini A, Fecal microbiota transplantation for the treatment of Clostridium difficile infection: a systematic review. J Clin Gastroenterol 2014; 48(8): 693-702.

322. Debast SB, Bauer MP, Kuijper EJ, et al., European Society of Clinical Microbiology and Infectious Diseases: update of the treatment guidance document for Clostridium difficile infection. Clin Microbiol Infect 2014; 20 : 126.

323. Cammarota G, Ianiro G, Tilg H, et al., European consensus conference on faecal microbiota transplantation in clinical practice. Gut 2017; 66(4): 569-580. 
324. Satokari R, Mattila E, Kainulainen V, et al., Simple faecal preparation and efficacy of frozen inoculum in faecal microbiota transplantation for recurrent Clostridium difficile infection-an observational cohort study. Aliment Pharmacol Ther 2015; 41(1): 46-53.

325. Moayyedi P, Surette MG, Kim PT, et al., Fecal microbiota transplantation induces remission in patients with active ulcerative colitis in a randomized controlled trial. Gastroenterology 2015; 149(1): 102-109. e6.

326. Vrieze A, Van Nood E, Holleman F, et al., Transfer of intestinal microbiota from lean donors increases insulin sensitivity in individuals with metabolic syndrome. Gastroenterology 2012; 143(4): 913-916. e7.

327. Allegretti JR, Kassam Z, Osman M, et al., The 5D framework: a clinical primer for fecal microbiota transplantation to treat Clostridium difficile infection. Gastrointest Endosc 2018; 87(1): 18-29.

328. Kim KO, Schwartz M, and Gluck M, 1011-Reducing Cost and Scheduling Complexity of Fecal Microbiota Transplantation by Using Universal Donor over Patients-Directed Donors in Patients with Recurrent Clostrodium Difficile Infections. Gastroenterology 2018; 154(6): S-191.

329. Kassam Z, Lee CH, Yuan Y, et al., Fecal Microbiota Transplantation for Clostridium difficile Infection: Systematic Review and Meta-Analysis. Am J Gastroenterol 2013; 108(4): 500-508.

330. Osman M, Stoltzner Z, O'Brien K, et al. Donor efficacy in fecal microbiota transplantation for recurrent clostridium difficile: evidence from a 1,999-patient cohort. in Open Forum Infectious Diseases. 2016. Oxford University Press.

331. Paramsothy S, Kamm MA, Kaakoush NO, et al., Multidonor intensive faecal microbiota transplantation for active ulcerative colitis: a randomised placebo-controlled trial. Lancet 2017; 389(10075): 1218-1228.

332. Kim KO and Gluck M, Fecal microbiota transplantation: an update on clinical practice. Clin Endosc 2019; 52(2): 137.

333. Smith M, Kassam Z, Edelstein C, et al., OpenBiome remains open to serve the medical community. Nat Biotechnol 2014; 32(9): 867-867.

334. Petrof EO, Gloor GB, Vanner SJ, et al., Stool substitute transplant therapy for the eradication of Clostridium difficile infection:'RePOOPulating'the gut. Microbiome 2013; 1(1): 3.

335. Kelly BJ and Tebas $\mathrm{P}$, Clinical practice and infrastructure review of fecal microbiota transplantation for Clostridium difficile infection. Chest 2018; 153(1): 266-277.

336. Yang Y, Tian J, and Yang B, Targeting gut microbiome: A novel and potential therapy for autism. Life Sci 2018; 194: 111-119.

337. Lee L-H, Ser H-L, Letchumanan V, et al., The role of gut microbiome in traditional Chinese medicine syndromes: focusing on the spleen deficiency syndrome. Gut 2020; 69(Suppl 2): A19.

Author(s) shall retain the copyright of their work and grant the Journal/Publisher right for the first publication with the work simultaneously licensed under:

Creative Commons Attribution-NonCommercial 4.0 International (CC BY-NC 4.0). This license allows for the copying, distribution and transmission of the work, provided the correct attribution of the original creator is stated. Adaptation and remixing are also permitted. 